\title{
DESIGN OF A TUNABLE HIGH-Q SUPERCONDUCTING NOTCH FILTER
}

by

Charles M. Falco, R. T. Kampwirth,

C. S. Pang, and Ivan Schuller

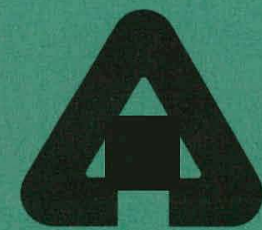

ARGONNE NATIONAL LABORATORY, ARGONNE, ILLINOIS

Prepared for the U. S. DEPARTMENT OF ENERGY

under Contract W-31-109-Eng-38 


\section{DISCLAIMER}

This report was prepared as an account of work sponsored by an agency of the United States Government. Neither the United States Government nor any agency Thereof, nor any of their employees, makes any warranty, express or implied, or assumes any legal liability or responsibility for the accuracy, completeness, or usefulness of any information, apparatus, product, or process disclosed, or represents that its use would not infringe privately owned rights. Reference herein to any specific commercial product, process, or service by trade name, trademark, manufacturer, or otherwise does not necessarily constitute or imply its endorsement, recommendation, or favoring by the United States Government or any agency thereof. The views and opinions of authors expressed herein do not necessarily state or reflect those of the United States Government or any agency thereof. 


\section{DISCLAIMER}

Portions of this document may be illegible in electronic image products. Images are produced from the best available original document. 
The facilities of Argonne National Laboratory are owned by the United States Government. Under the terms of a contract (W-31-109-Eng-38) between the U. S. Department of Energy, Argonne Universities Association and The University of Chicago, the University employs the staff and operates the Laboratory in accordance with policies and programs formulated, approved and reviewed by the Association.

\section{MEMBERS OF ARGONNE UNIVERSITIES ASSOCIATION}

The University of Arizona Carnegie-Mellon University Case Western Reserve University The University of Chicago

University of Cincinnati Illinois Institute of Technology University of Illinois Indiana University Iowa State University The University of Iowa
Kansas State University The University of Kansas Loyola University Marquette University Michigan State University The University of Michigan University of Minnesota University of Missouri Northwestern University University of Notre Dame
The Ohio State University Ohio University The Pennsylvania State University Purdue University

Saint Louis University Southern Illinois University The University of Texas at Austin Washington University Wayne State University The University of Wisconsin

\section{NOTICE}

This report was prepared as an account of work sponsored by the United States Government. Neither the United States nor the United States Department of Energy, nor any of their employees, nor any of their contractors, subcontractors, or their employees, makes any warranty, express or implied, or assumes any legal liability or responsibility for the accuracy, completeness or usefulness of any information, apparatus, product or process disclosed, or represents that its use would not infringe privately-owned rights. Mention of commercial products, their manufacturers, or their suppliers in this publication does not imply or connote approval or disapproval of the product by Argonne National Laboratory or the U. S. Department of Energy.

Printed in the United States of America Available from

National Technical Information Service

U. S. Department of Commerce

5285 Port Royal Road

Springfield, Virginia 22161

Price: Printed Copy $\$ 4.50 ;$ Microfiche $\$ 3.00$ 


\section{ARGONNE NATIONAL LABORATORY 9700 South Cass Avenue Argonne, Illinois 60439}

DESIGN OF A TUNABLE HIGH-Q SUPERCONDUCT ING NOTCH FILTER

by

Charles M. Falco, R. T. Kampwirth, C. S. Pang, and Ivan Schuller

Solid State Science Division
This report was prepared as an account of work This repon was prepared as an acoun of work Sponsored by the Uniled Stas Government. Nesher die Enerd Stes nor the Uniled Slates Department of Energy, nor any or their employees, nor any of their contractors, subcontractors, or heir, employes, makes any warranty, express or implied, or assumes any legal liability or responsibility for the accuracy, completeness or usefulness of any information, apparatus, product or
process disclosed, or represents that its use would not infitinge privalely uwied tiglits. 
THIS PAGE

\section{WAS INTENTIONALLY LEFT BLANK}


TABLE OF CONTENTS

Page

Abstract . . . . . . . . . . . . . . . . . . . 1

A. Filter Design

I. Tntrndurtinn ..................... 2

II. Cryogenics . . . . . . . . . . . . . . 2

III. Actual Filter Design . . . . . . . . . . . . . . 2

IV. Electrical Considerations . . . . . . . . . . 10

1. Calculation of Mutual Inductance Between $\mathrm{L}_{1}$ and $\mathrm{L}_{2}$. 10

2. Calculation of Capacitance $\mathrm{C}_{2}$. . . . . . . . . . 11

3. Resistance . . . . . . . . . . . . . . 11

4. Calculation of Vibrations Effects on Capacitance . . 14.

B. Superconducting Film Preparation and Characterization

I. Substrate . . . . . . . . . . . . . . . 17

TI. Substrate Heating . . . . . . . . . . . . . . . 17

III. Superconducting Films and Their Properties. . . . . . . 19

a. Niobium . . . . . . . . . . . . . . 19

b. Niobium Nitride . . . . . . . . . . . . 22

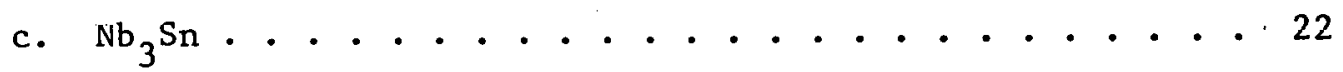

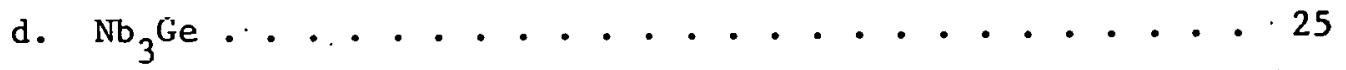

IV. Etched Pattern Development. . . . . . . . . . . . 27

V. Film Preparation Facilities . . . . . . . . . ... 32

References . . . . . . . . . . . . . . . . . . 33 
1. Helium dewar . . . . . . . . . . . . . . . 3

2. Support table... . . . . . . . . . . . . . . 4

3. Cryostat plateform . . . . . . . . . . . . . . 4

4. Cryostat-probe coupling and vibration decoupler. . . . . . . 5

5. Vibration decoupler detail . . . . . . . . . . . . . 5

6. Positioning of support rods for the decoupler. . . . . . . . . 6

7. Cryostat-probe coupling detail . . . . . . . . . . . 7

8. Basic circuit of the notch filter. . . . . . . . . . . . 7

9. The actual circuit design. . . . . . . . . . . . . . 8

10. Primary induction coil of the actual circuit . . . . . . . . 8

11. Secondary induction coil with ends terminated on the capacitor plates... . . . . . . . . . . . . . . . 8

12. Capacitor plates . . . . . . . . . . . . . . 8

13. High temperature probe and filter housing. . . . . . . . . . 12

14. Cryostat top plate with micrometer head for tuning control . . 12

15. Basic circuit design limits for desired notch shape. . . . . . 13

16. Capacitor plates will dielectric showing lateral vibration . . 13

17. Substrate heater using thermocoax heating elements embedded in $\mathrm{Ni} / \mathrm{Cu}$ plate. . . . . . . . . . . . . . . . . . . 20

18. Microstructure of sputtered $\mathrm{Nb}$ film. . . . . . . . . . . 23

19. Microstructure of sputtered $\mathrm{Nb}$ film. . . . . . . . . . . . 24

20. SEM micrograph of $\mathrm{Nb}_{3} \mathrm{Sn}$ film indicates columnar growth structure 26

21. Reacted $\mathrm{Nb}-\mathrm{Sn}$ powder sputtering target . . . . . . . . . 26 


\section{LIST OF FIGURES (Cont.)}

$\underline{\text { Page }}$

22. Examples of etching defects occurred in the $\mathrm{Nb}$ film coil on Pyrex substrate . . . . . . . . . . . . . . 28

23. Improved etching pattern of $\mathrm{Nb}$ film coil on fused silica substrate .......................... 29

24. Perfectly ectched Nb film coil. . . . . . . . . . . . 30 
DESIGN OF A TUNABLE HIGH-Q

SỤPERCONDUCTING NOTCH FILTER

by.

Charles M. Falco, R. T. Kampwirth,

C. S. Pang, and Ivan Schuller

\begin{abstract}
- We report on the design of a tunable high-Q superconducting notch filter. The filter is designed to be manufactured from high $\mathrm{T}_{\mathrm{c}}$ superconductors $\left(\mathrm{Nb}_{3} \mathrm{Sn}, \mathrm{Nb}_{3} \mathrm{Ge}\right)$ made by high-rate magnetron sputtering on sapphire substrates.

We report on considerations relating to the geometry of the various elements, on holder materials for the cryostat, on studies relating to the preparation of suitable high $\mathrm{T}_{\mathrm{c}}$ materials, and on the photoetching procedures for the filter elements.
\end{abstract}




\section{A. Filter Design}

\section{INTRODUCTION}

In general the filter design aspect can be broken down into 3 major categories: cryogenics, actual filter design and electronics. Roughly speaking the cryogenics has to include a variable temperature cryostat of large enough size to house the filter, appropriate thermometers, vacuum pumps and vibration isolators to decouple mechanical vibrations from the cryostat. The actual filter design includes selection of support materials for the substrate that have the appropriate mechanical, cryogenic and electrical properties and the design of low temperature vacuum sealed feedthroghs for frequency tuning. The electronics deals with sturies relating to coaxial lines for signal transmission, electronic apparatus and shielding from environmental rf noise. Must of the design and description of materials is appropriate for both the flat and the cylindrical geometries. To be more specific, we will use as a prototype one of the flat geometry designs made from niobium films deposited on fused quartz substrates.

\section{CRYOGENICS}

Fig. 1 shows a sketch of the glass dewar that will accomodate the variable temperature cryostat. The large (4") I.D. of the helium dewar is necessary to accomodate the $2^{\prime \prime}$ diameter substrates and their holders. Figs. 2 and 3 show the table and plate from which the dewar is suspended. In order to avoid coupling of vibration from the pumps to the cryostat the 4" pumping lines will be fed to the dewar through the vibration decoupler shown in Figs. 4, 5, 6, and 7 . The effect of the vibratione on the performance of the filter will be discussed in detail in Section A-IV-4.

The cryostat consists of a double walled variable temperature insert for the helium dewar. The temperatures are measured using Ge thermometors and controlled to better than $1 \mathrm{mK}$ by either requesting the bath pressure 、 or by using a SHE model ATC temperature controller.

\section{ACTUAL FILTER DESIGN}

An equivalent circuit for the planar filter is shown in Fig. 8 . The various elements are evaporated on 2 "diameter sapphire substrates and are shown in Figs. 9, 10, 11 and 12. The calculations performed in Section A-IV-2 show that the spacing between plate $\mathrm{C}_{2}$ and $\mathrm{L}_{2}$ should be in the $\mathrm{cm}$ range and the spacing between $\mathrm{L}_{1}$ and $\mathrm{L}_{2}$ should be variable between .001" and $\sim .060^{\prime \prime}$ in order to be able to span an appreciable fraction of the frequency range as well as the required notch shape over which the final filter operates. In brief, the substrates should be mounted on holders made out of a material of low dielectric constant and low loss tangent in order to avoid appreciable distortions of the fringing fields as well as the dielectric losses which may limit the $Q$. The holder of material should have thermal expansion coefficients closely matching that of sapphire; furthermore, it should be machinable and should be mechanically rugged. 


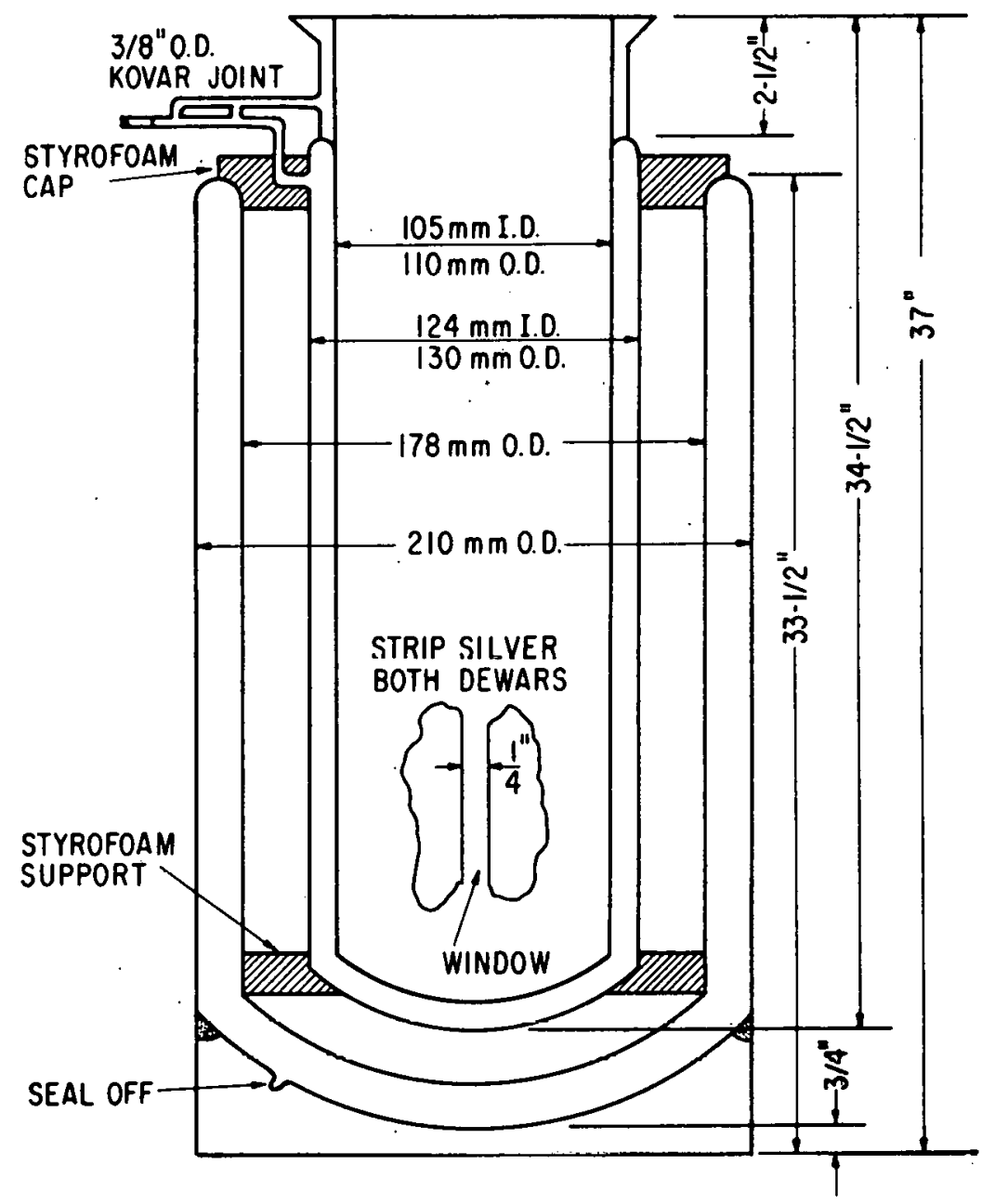

Fig. 1 Helium dewar 


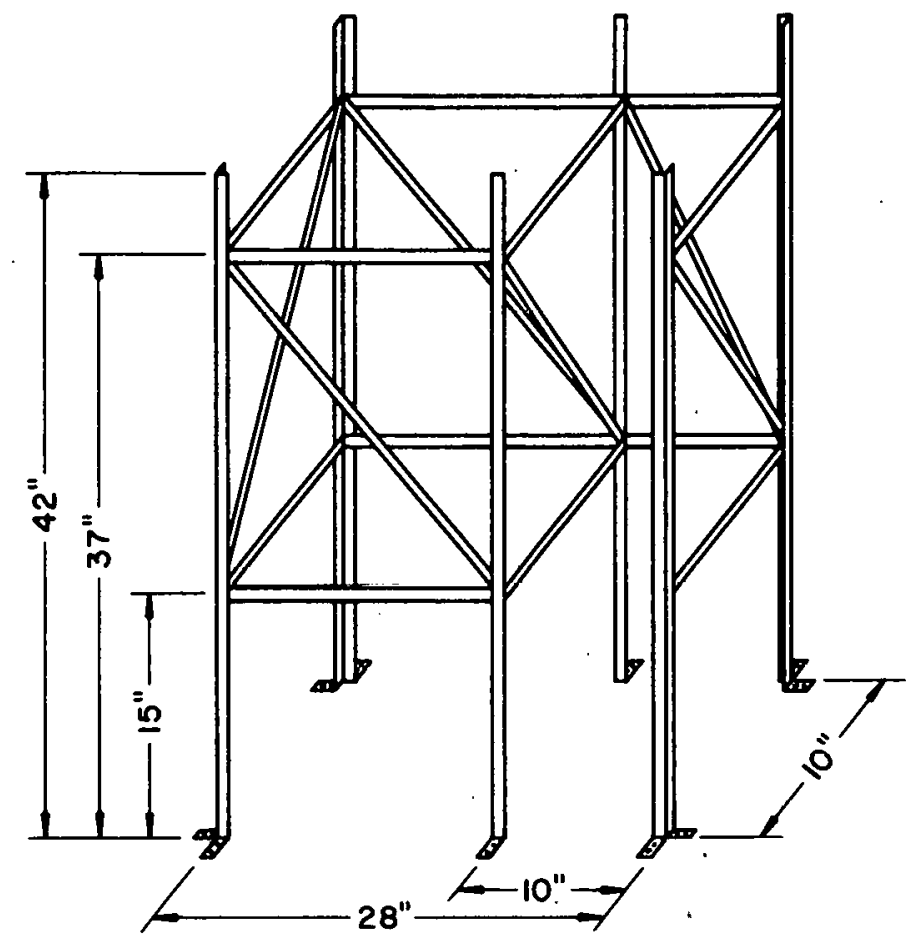

Fig. 2 Support table

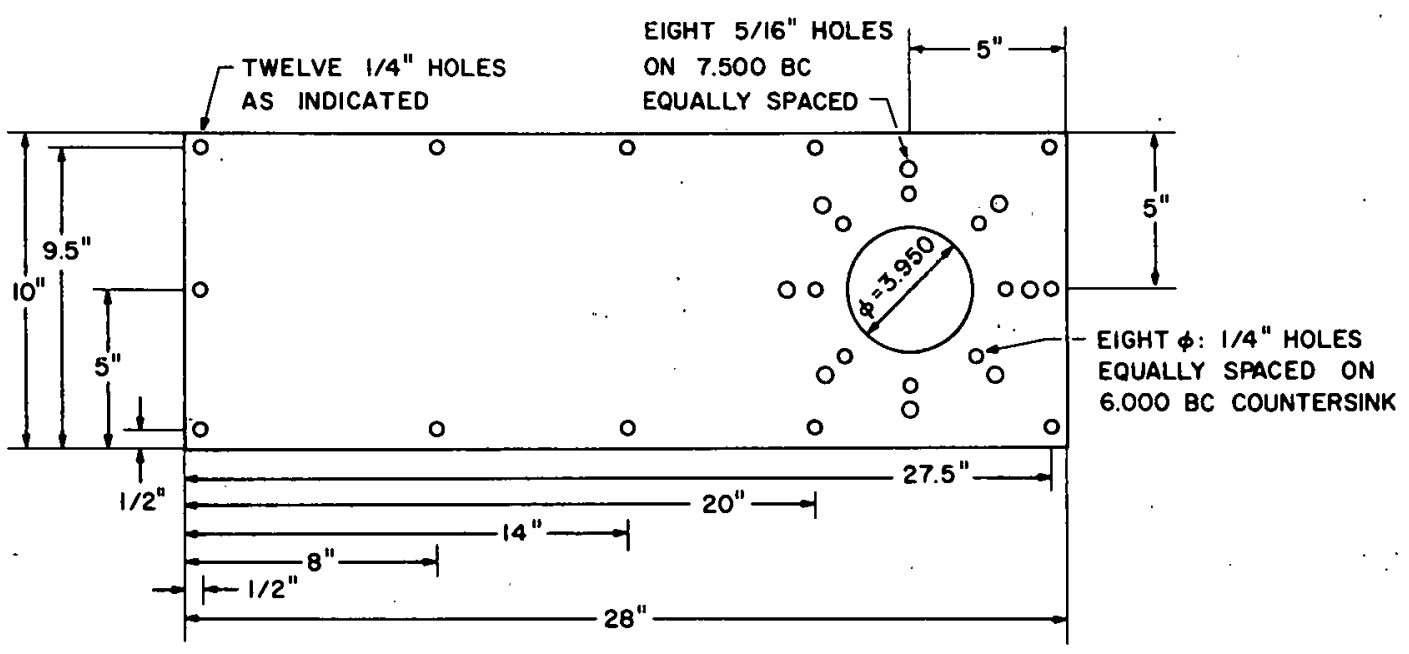

Fig. 3 Cryostat plateform 


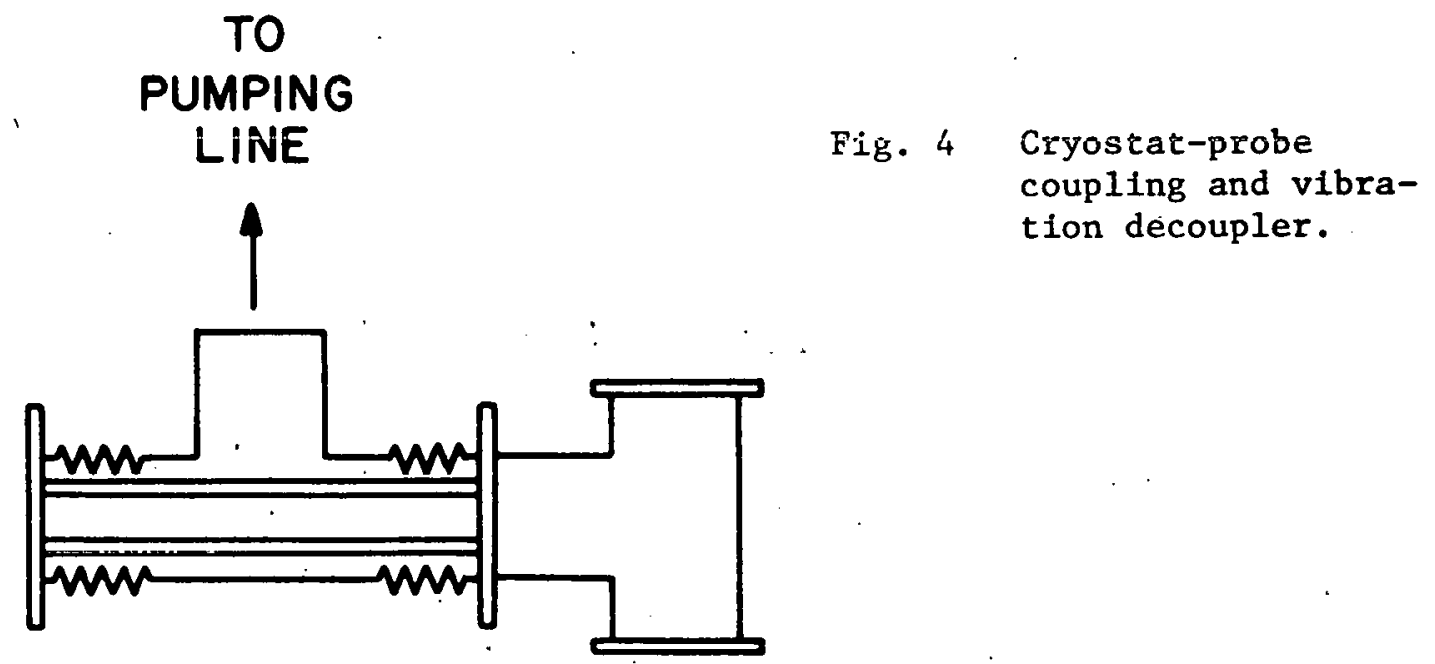

Fig. 5 Vibration decoupler detail.

TO

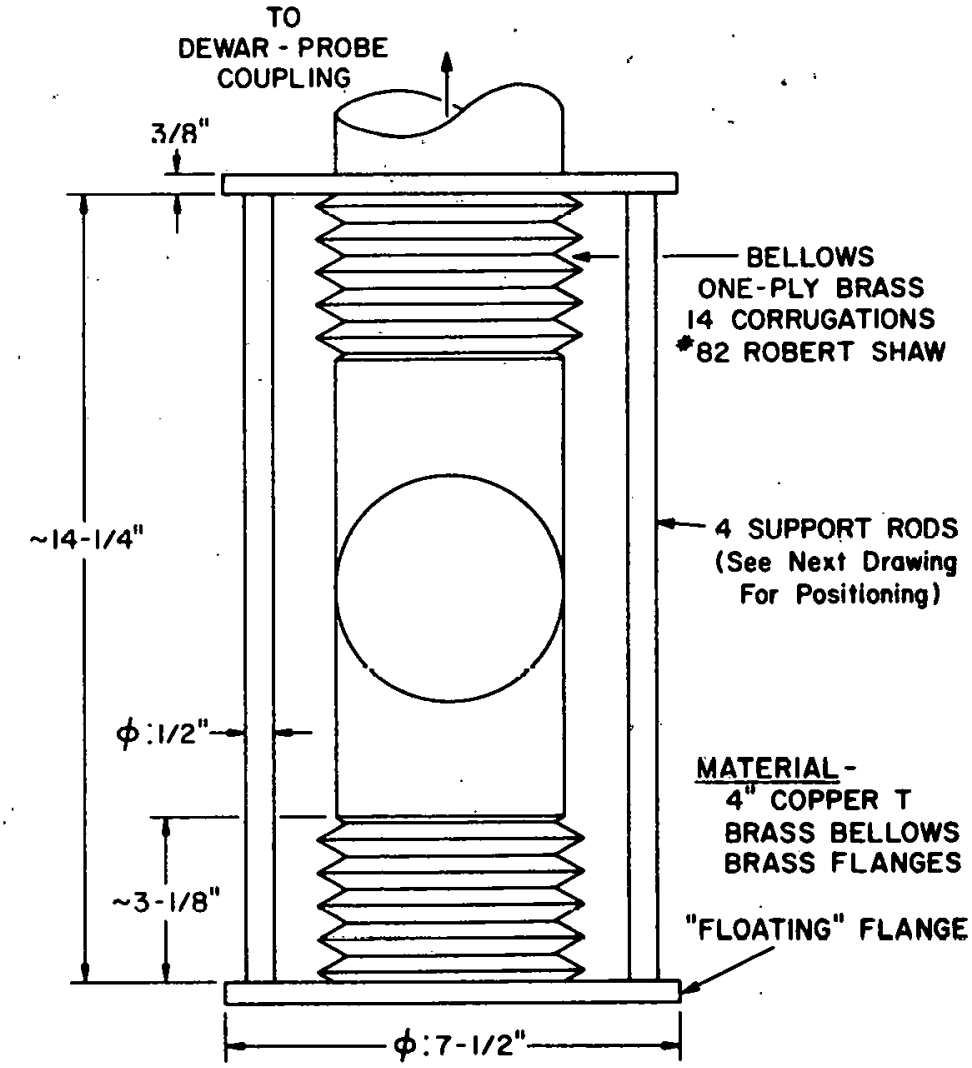




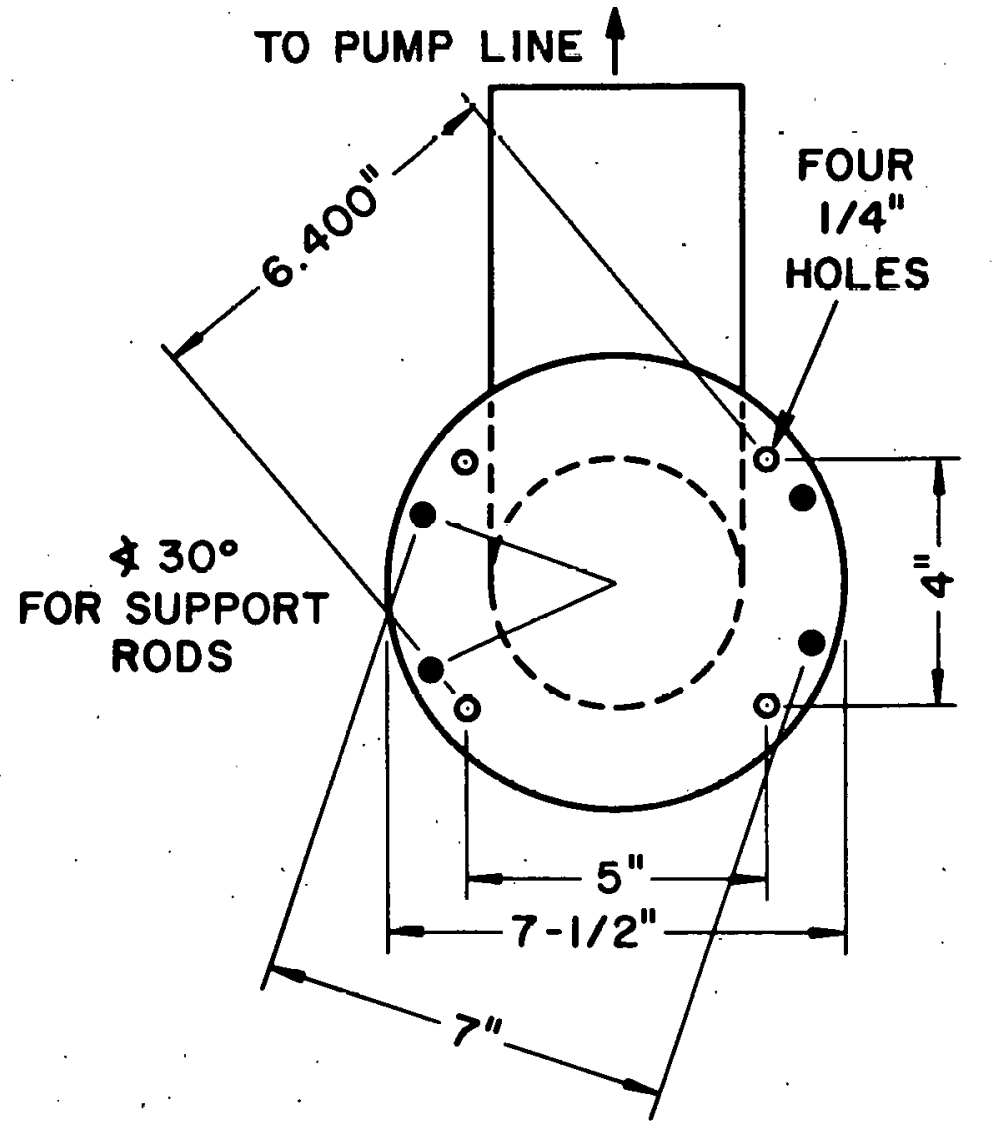

Fig. 6 Positioning of support rods for the decoupler. 


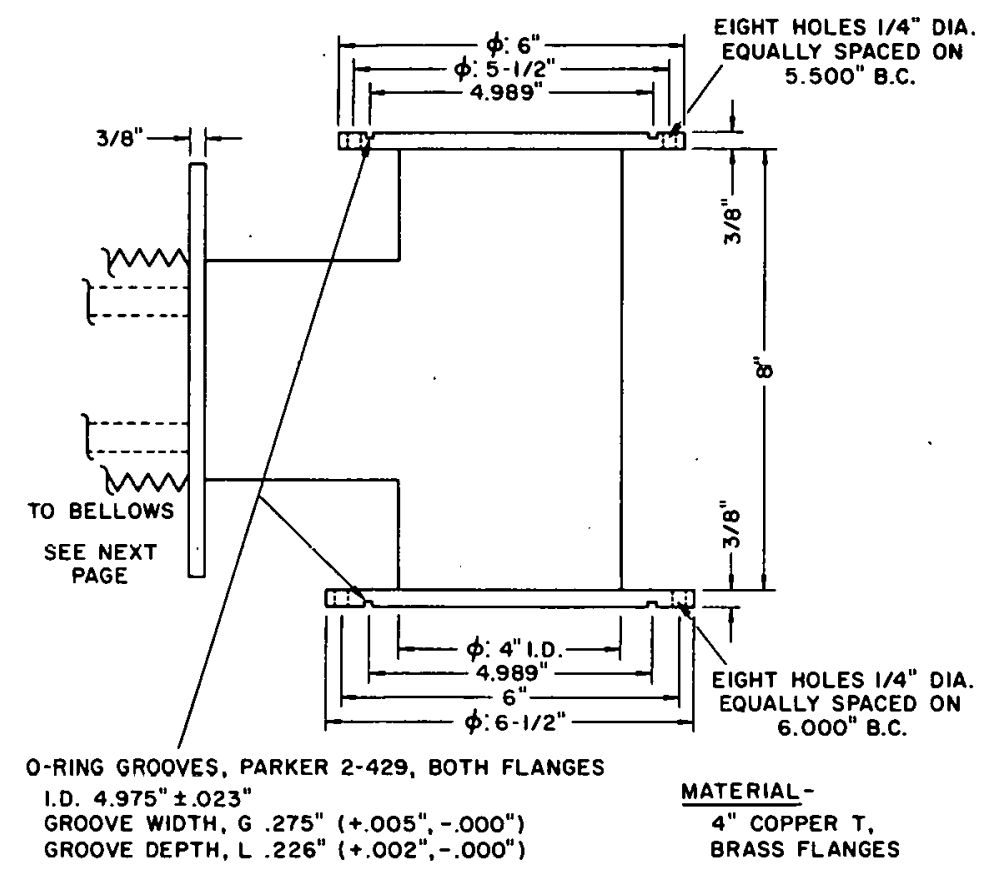

Fig. 7 Cryostat-probe coupling detail.

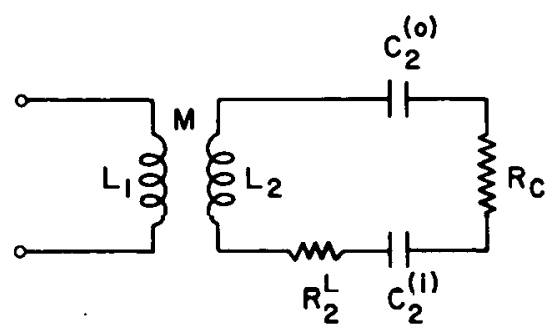

$L_{1}=40 \mu \mathrm{H}$

Fig. 8 Basic circuit of the notch

$\mathrm{L}_{2}=211 \mu \mathrm{H}$

$M \cong 24 \mu \mathrm{H}$ FOR $1 \mathrm{~cm}$ SPACING

$\mathrm{C}_{2}^{(0)}=$ OUTER CAPACITOR

$C_{2}^{(1)}=$ INNER CAPACITOR

$R_{C}=$ POSSIBLE LOSSES IN / BETWEEN $C_{2}^{0}$ AND/OR $C_{2}^{\prime}$

$R_{2}^{L}=$ POSSIBLE LOSSES IN $L_{2}$ 


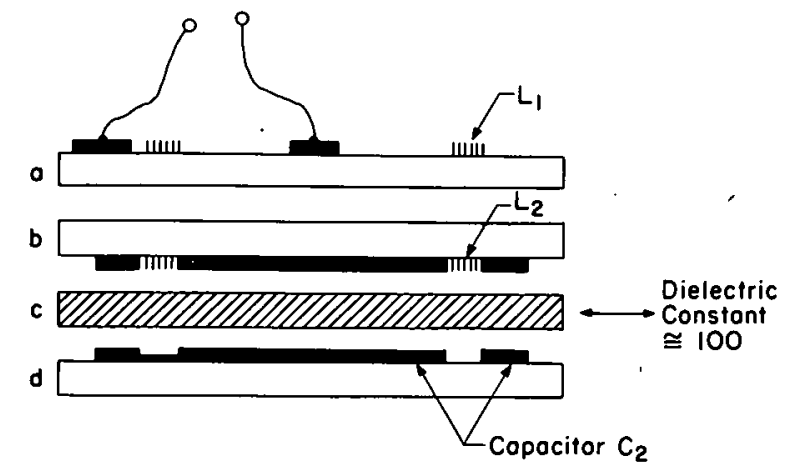

Fig. 9 The actual circuit design

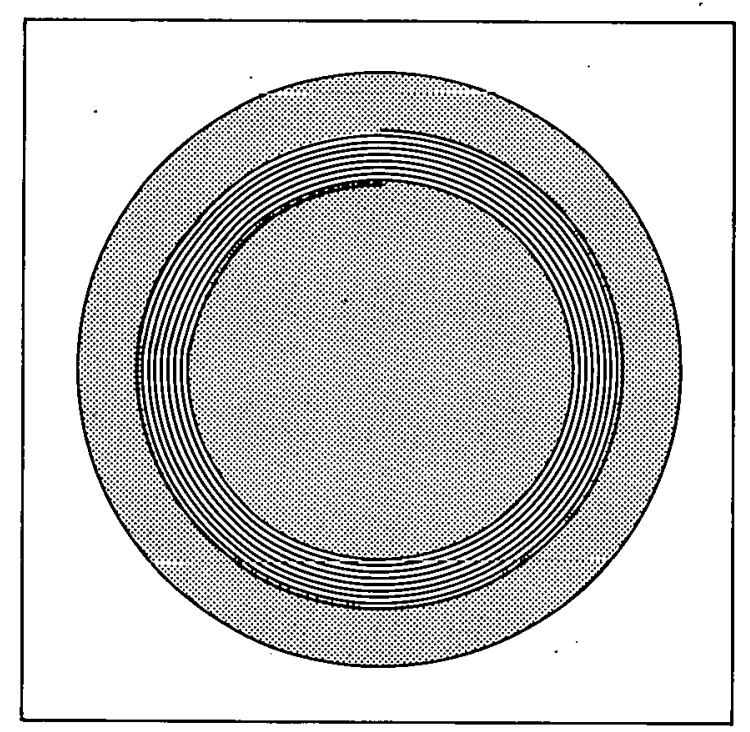

SPIRAL INDUCTOR $L_{2}$ $0.002^{\prime \prime}$ line on $0.003^{\prime \prime}$ centers Approx. 58 turns

Approx. $211 \mu \mathrm{H}$

Fig. 11 Secondary induction coil with ends terminated on the capacitor plates.

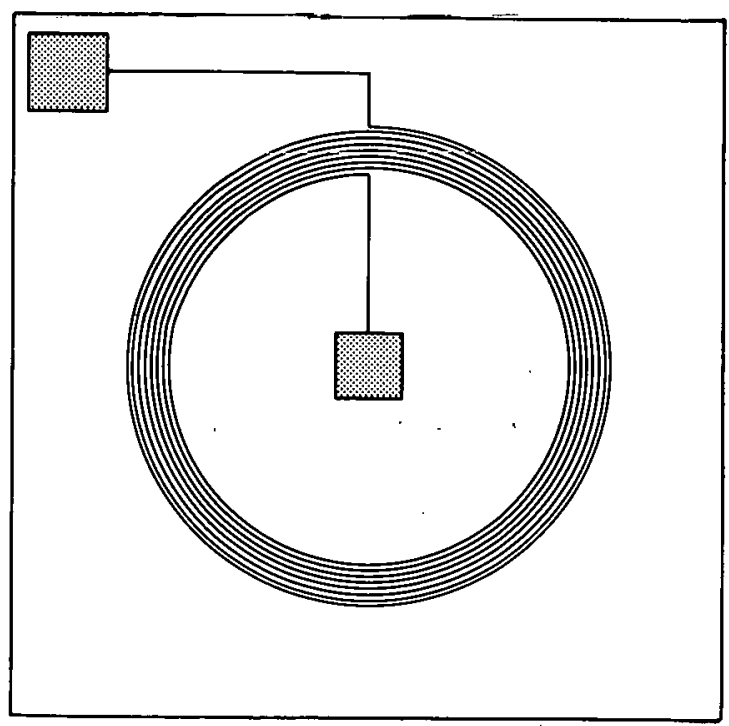

SPIRAL INDIICTOR L L 0.002 " line on 0.0071 " centers Approx. 25 furns Approx. $40 \mu \mathrm{H}$

Fig. 10 Primary induction coil of the actual circuit.

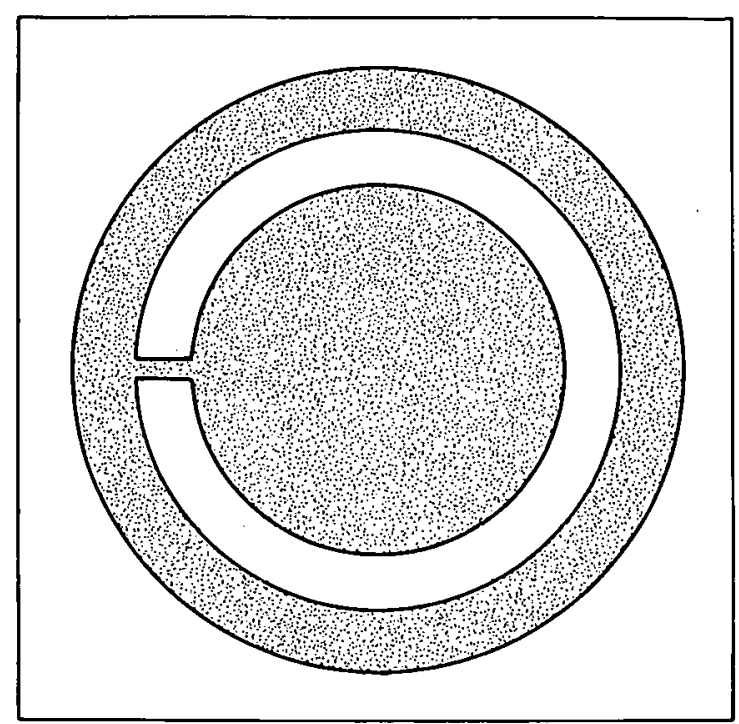

CAPACITOR $\mathrm{C}_{2}$ (Bottom Plate)

Fig. 12 Capacitor plates. 
Roughly speaking the $Q$ of the circuit is given as

$$
\frac{1}{Q}=\frac{1}{Q_{R}}+\frac{1}{Q_{D}}+\frac{1}{Q_{r}}+\frac{1}{Q_{c}}
$$

where $Q_{R}$ relates to the resistance in the tank circuit, $Q_{D}$ relates to the dielectric losses which are proportional to the loss tangent of the dielectric material in the circuit, $Q_{r}$ relates to the radiation loss which can be minimized if good shielding is provided, and $Q_{c}$ is related to the coupling loss.

Table I. shows a list of the thermal expansion coefficients, dielectric constants and loss tangents of relevant holder materials.

TABLE I

Construction Materials For Filter Support

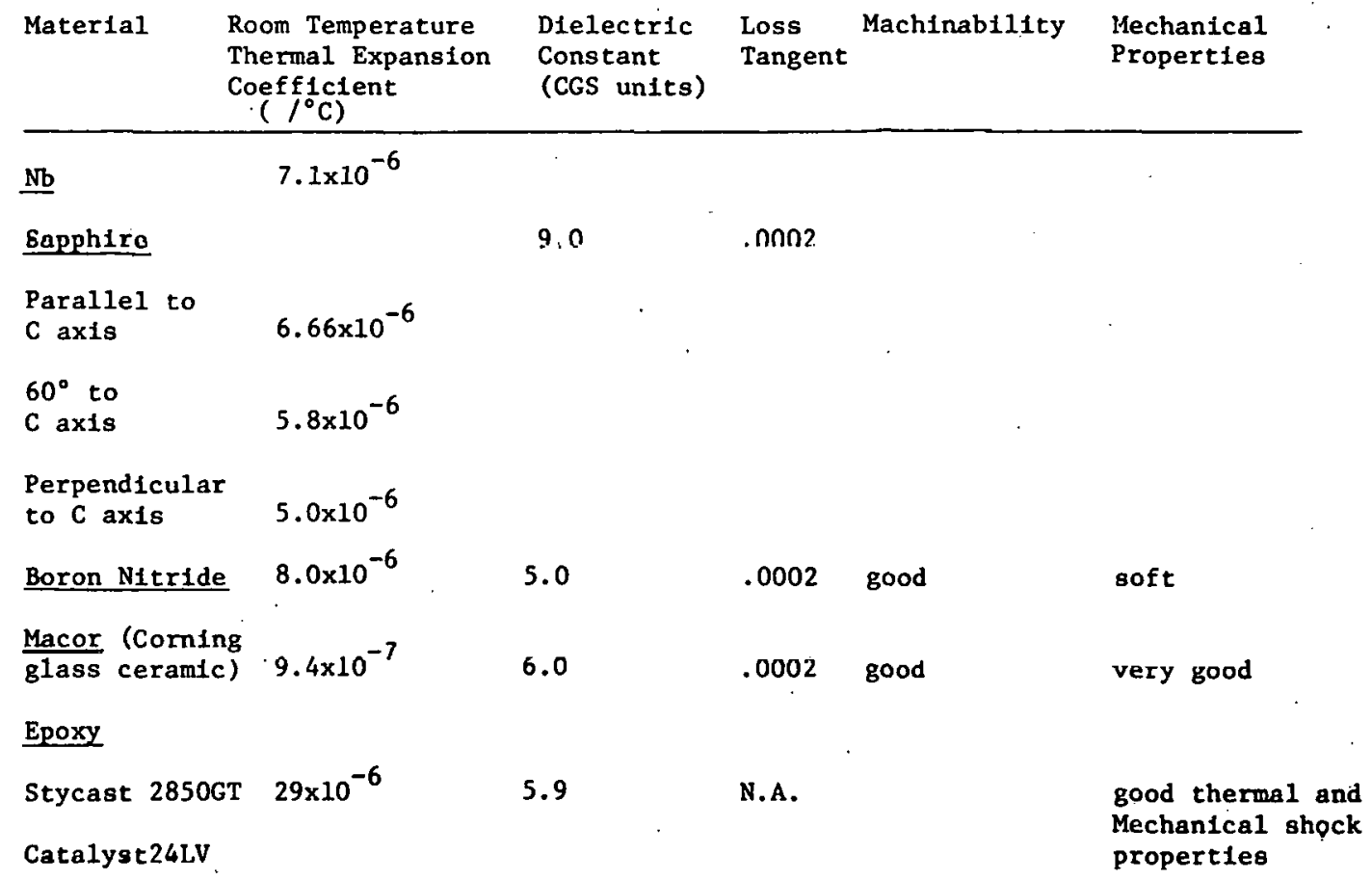


According to Table I there are two choices for holder materials: Boron Nitride and Macor. Both have thermal expansion coefficients close to that of sapphire, suitable mechanical properties, high dielectric constants and low loss tangents.

In an attempt to simplify the design problem, $\mathrm{Nb}$ was deposited on high temperature $\left(\sim 500^{\circ} \mathrm{C}\right)$ Boron Nitride substrates. The resulting films were of very poor quality so that no further work was conducted using Boron Nitride as a substrate material.

The filter assembly concept is shown in Figs. 13, 14. Capacitor plate $\mathrm{C}_{2}$ is adjusted by means of a Mitutoyo-297-101 nonrotating micrometer head. The movable shaft is sealed to the feedthru with a double o-ring. Inductors $\mathrm{L}_{1}$ and $\mathrm{L}_{2}$ can be kept separate by using suitable spacers and a dielectric can be inserted between $\mathrm{L}_{2}$ and $\mathrm{C}_{2}$ in order to increase the frequency range.

IV. ELECTRICAL CUNSLDERAIIUNS

1. Calculation of Mutual Inductance Between $L_{1}$ and $L_{2}$

To make an approximate calculation of the mutual inductance between $\mathrm{L}_{1}$ and $\mathrm{L}_{2}$ we will calculate the mutual inductance between the innermost set and outermost set of coils. These values will then be averaged and multiplied by the total number of turns. For two coils of radius a and separation $\underline{d}$, the mutual inductance is given by $M_{0}=f a$ where $\underline{f}$ is a function of $\frac{\mathrm{d}}{2 \mathrm{a}}$ and is tabulated numerically by Grover table 16 , $M_{\text {tota } 1 .}=M_{n} \times N_{1} \times N_{2}$ and $\mathrm{K}=\mathrm{M} / \sqrt{\mathrm{L}_{1} \mathrm{~L}_{2}}$.

Table II shows the various parameters and the average mutual inductance for two different separations.

TABLE II

\begin{tabular}{|c|c|c|c|c|c|c|c|}
\hline $\begin{array}{c}\mathrm{d} \\
{[\mathrm{cm}]}\end{array}$ & & $\stackrel{\mathrm{a}}{[\mathrm{cm}]}$ & $d / 2 a$ & $\begin{array}{c}\mathrm{f} \\
{[\mu \mathrm{H} / \mathrm{cm}]}\end{array}$ & $\begin{array}{c}\mathrm{M}_{\mathrm{O}} \\
{[\mu \mathrm{H}]}\end{array}$ & $\overline{\mathrm{M}}_{0}$ average & $\begin{array}{c}\text { M total } \\
{[\mu \mathrm{H}]}\end{array}$ \\
\hline \multirow{2}{*}{0.5} & innermost & 1.4936 & .168 & .01580 & .02368 & \multirow{2}{*}{.02961} & \multirow[t]{2}{*}{42.93} \\
\hline & outermost & 1.9291 & .130 & .01842 & .03553 & & \\
\hline \multirow{2}{*}{1.0} & innermost & 1.4986 & .3336 & .008213 & .011231 & \multirow{2}{*}{.01685} & \multirow{2}{*}{24.43} \\
\hline & outermost & 1.9291 & .2592 & .011086 & .02139 & & \\
\hline
\end{tabular}

${ }^{*}{ }_{1962}$. Grover, Inductance Calculations, p. 83, Dover Publications. New York, 
As shown in Table I.I the coupling constant can be easily adjusted to be in the range $0.25<\mathrm{K}<0.5$ using reasonable separations between $\mathrm{L}_{1}$ and $\mathrm{L}_{2}$

2. Calculation of Capacitance $\mathrm{C}_{2}$

The calculation of the capacitance is based on the fact that $\mathrm{C}_{2}$ is made of two circular capacitors in parallel. For a parallel plate capacitor

$$
C=-\frac{\varepsilon_{0}^{A}}{d} \text { where } \varepsilon_{0} \simeq 8.854 \times 10^{-12} \mathrm{C}^{2} \mathrm{~J}^{-1} \mathrm{~m}^{-1}
$$

for vacuum. Table III shows the relevant parameters for the two capacitors, for two different separations.

TABLE III

$$
\mathrm{d}=1 \mathrm{~cm}=10^{-2} \mathrm{~m} \quad \mathrm{~d}=0.1 \mathrm{~cm}=10^{-3} \mathrm{~m}
$$

\begin{tabular}{|c|c|c|c|c|c|c|c|}
\hline & $\begin{array}{c}r_{1} \\
{[\mathrm{~cm}]}\end{array}$ & $\begin{array}{c}r_{2} \\
{[\mathrm{~cm}]}\end{array}$ & $\frac{A}{\left[10^{-4} \mathrm{~m}^{2}\right]}$ & $\begin{array}{c}C \\
{[\mathrm{pF}]}\end{array}$ & $\begin{array}{c}C_{\text {total }} \\
{[\mathrm{pF}]}\end{array}$ & $\begin{array}{c}\mathrm{C} \\
{[\mathrm{pF}]}\end{array}$ & $\begin{array}{l}\mathrm{C}_{\text {total }} \\
{[\mathrm{pF}]}\end{array}$ \\
\hline inner & 0 & 1.4986 & 7.055 & 0.625 & \multirow{2}{*}{0.315} & 6.25 & \multirow{2}{*}{3.15} \\
\hline outer & 1.929 & 2.451 & 7.1828 & 0.636 & & 6.36 & \\
\hline
\end{tabular}

These capacitances can be increased by at least a factor of 100 using the appropriate dielectric filling. However, a careful selection of this filling material should be made such that the loss tangent does not lower the $Q$ significantly.

\section{Resistance}

For an acceptable notch shape $\mathrm{L}_{2}=211 \mu \mathrm{H}, \mathrm{R}_{2}$ must be less than $0.32 \Omega$ (See Fig. 15).

Assuming resistive transitions of maximum $0.5 \mathrm{~K}$ (which can be easily achieved in our sputtering systems) the resistance $R \frac{1}{2}$ and $R_{c}$ (See Fig. 8) should be smaller than a few $\mathrm{n} \Omega$ at temperatures below $18^{\circ} \mathrm{K}$ for $\mathrm{Nb}_{3} \mathrm{Sn}$ below $21^{\circ} \mathrm{K}$ for $\mathrm{Nb}_{3} \mathrm{Ge}$ and below $7.5^{\circ} \mathrm{K}$ for $\mathrm{Nb}$. Thus the resistance is not a limiting factor on the notch shape and $Q$. 


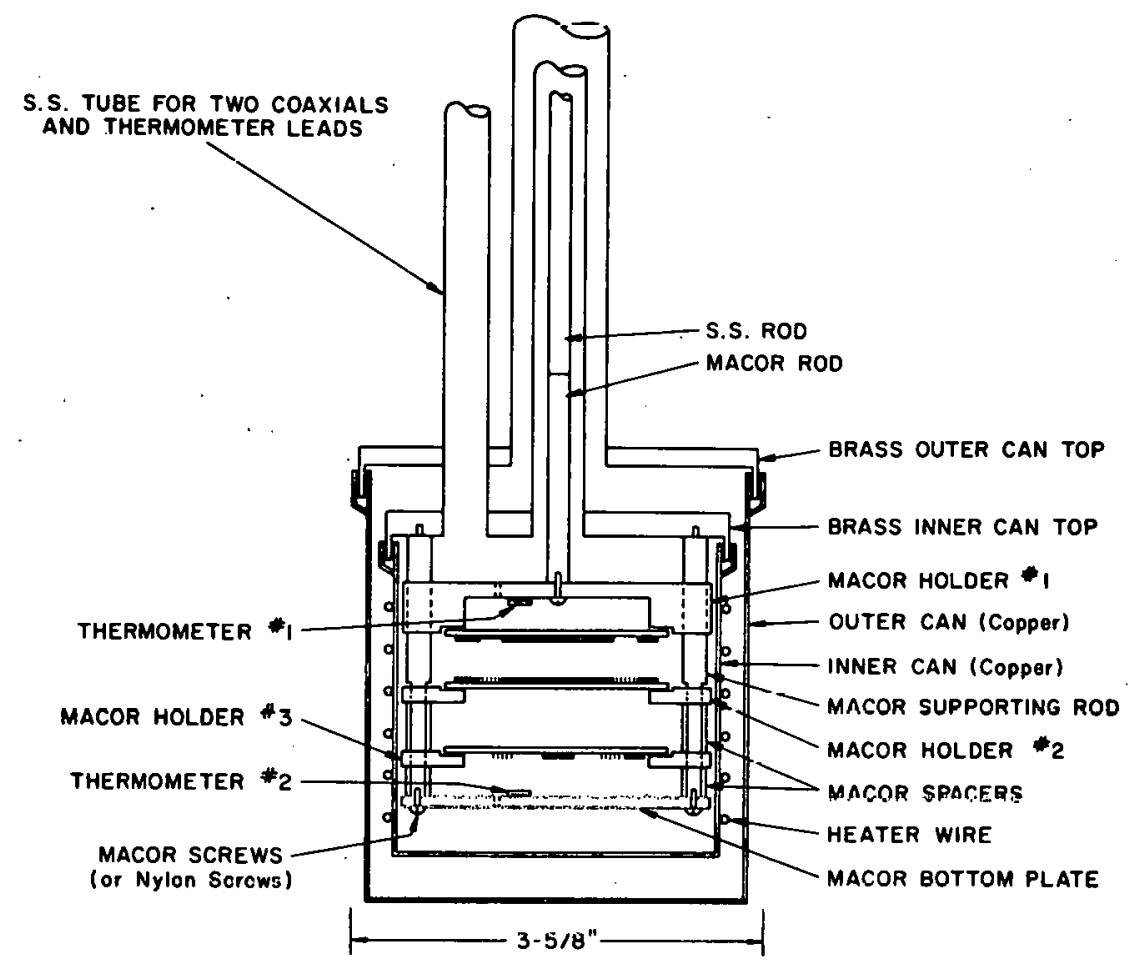

Fig. 13 High temperature probe and filter housing.

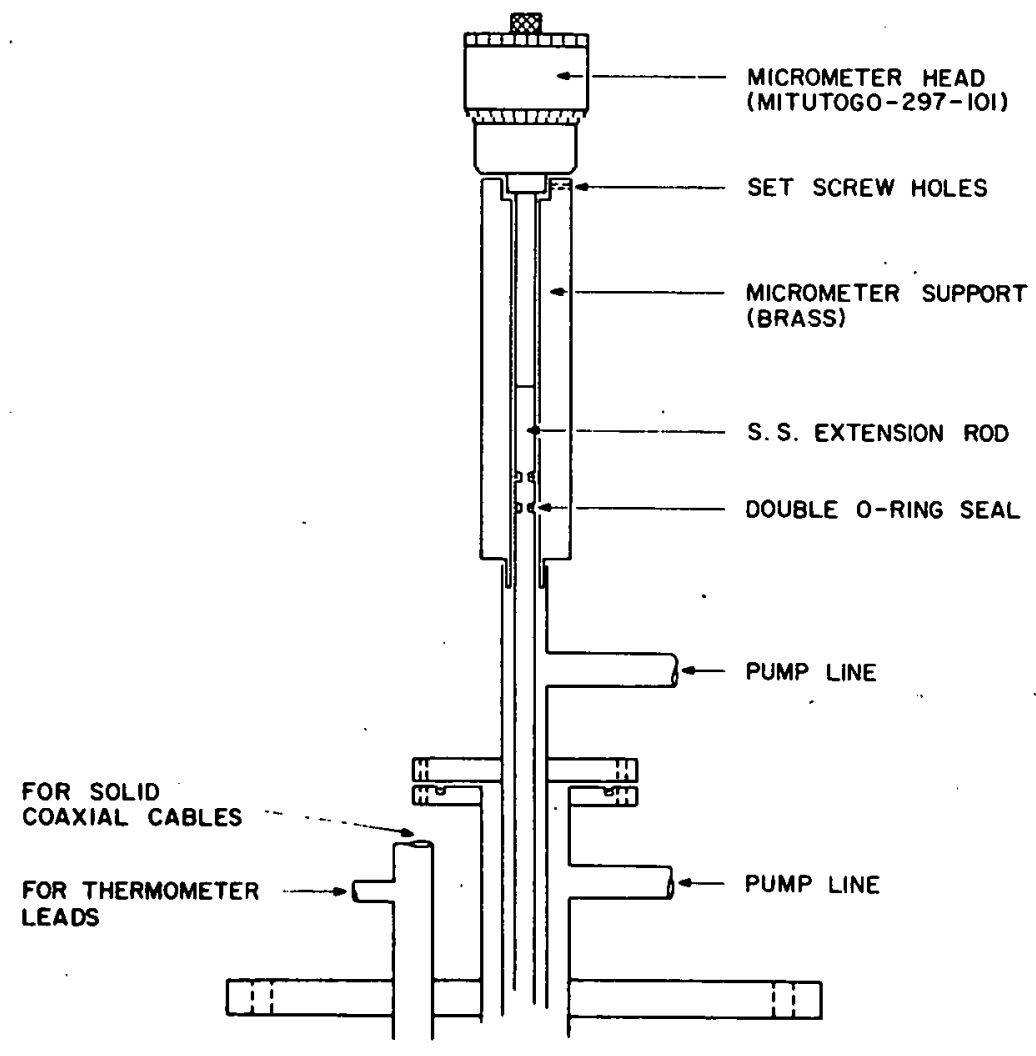

Fig. 14 Cryostat top plate with micrometer head for tuning control. 


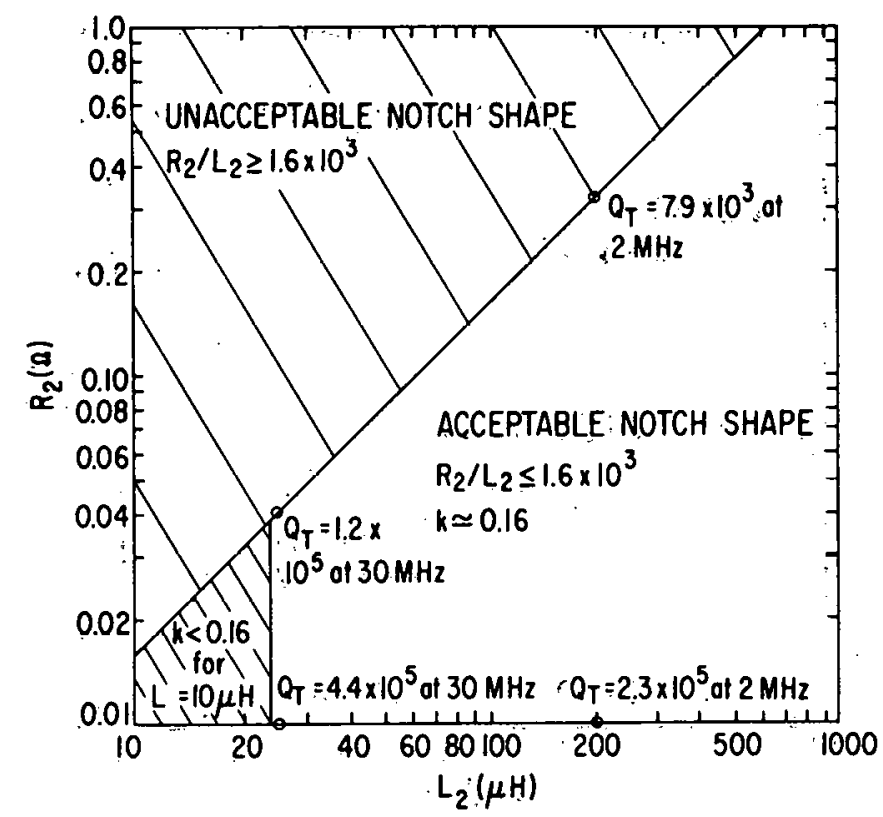

Fig. 15 Basic circuit design limits for desired notch shape.
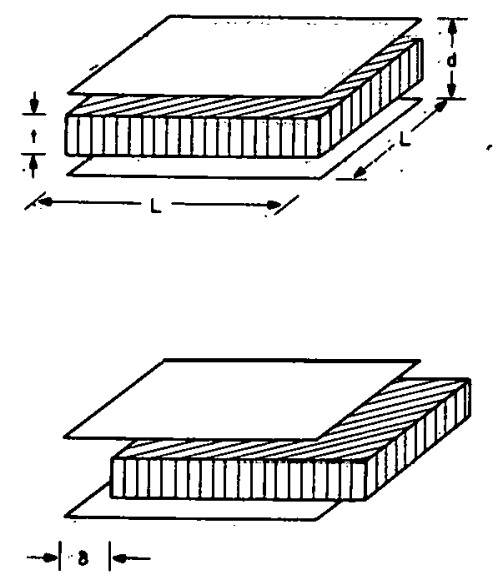

Fig. 16 Capacitor plates with dielectric showing lateral vibration. 


\section{Calculation of Vibrations Effects on Capacitance}

For parallel plates, $\mathrm{C}=\frac{\varepsilon \mathrm{A}}{\mathrm{d}}$, and $\varepsilon_{\mathrm{o}} \cong 8.854 \times 10^{-12} \mathrm{C}^{2} \mathrm{~J}^{-1} \mathrm{~m}^{-1}$. Assume a filling plug is used with $\varepsilon=100$ and filling factor .5 as shown in Fig. $16, C=3.12 \times 10^{-13} \cong 0.3 \mathrm{pF}$ and the resonant frequency $\mathrm{f}_{0}$ will be $19.6 \mathrm{MHz}$. The total volume of the dielectric is $3.53 \mathrm{~cm}^{3}\left(3.53 \mathrm{x}^{-10}-6 \mathrm{~m}^{3}\right)$. When the dielectric vibrates in one plane, the filing factor changes. As shown in Fig. 16(b), the effective area of the dielectric within the capacitor is

$$
\mathrm{A}_{\text {diel }}=\mathrm{L}(\mathrm{L}-\delta)
$$

The effective area of the "vacuum" is $L \delta$ so that

$$
C_{d 1 e 1}=\frac{\varepsilon \Lambda_{\text {diel }}}{d} \times \frac{t}{d}=\frac{\varepsilon L(L-\delta) t}{d_{2}}(\equiv 19.5 \mathrm{pF} \text { for } \delta=10 \mathrm{~m})
$$

and

$$
\begin{aligned}
C_{\text {vac }} & =\frac{\varepsilon_{0} A \text { vac }}{d}+\frac{\varepsilon_{0} A_{\text {diel }}}{d} \frac{(d-t)}{d} \\
& =\frac{\varepsilon_{0} L \delta}{d}+\frac{\varepsilon_{0} L(L-\delta)(d-t)}{d^{2}} \quad\left(=0.23_{p F}+0.20_{p F} \text { for } \delta=-1 c m\right)
\end{aligned}
$$

To calculate the vibrational effect, we need to differentiate to get

$$
\begin{aligned}
\frac{\partial C}{\partial \delta} & =-\frac{\varepsilon L t}{d^{2}}+\frac{\varepsilon_{0} L}{d}+\frac{\varepsilon_{0} L(t-d)}{d^{2}} \\
& =\frac{\varepsilon_{0} L}{d^{2}}[\varepsilon t+d+(t-d)]= \\
& =\frac{\varepsilon_{0} L}{d^{2}} t(\varepsilon+1)=1.189 \times 10^{-9} \mathrm{~F} / \mathrm{m} \cong 1.19 \mathrm{pF} / \mathrm{mm}
\end{aligned}
$$

The capacitance changes by approximately $6 \%$ per mm of travel. The design criteria dictate that $\mathrm{R}_{2} / \mathrm{L}_{2} \leq 1.6 \times 10^{3}$ over the intended tuning range so that

$$
\begin{aligned}
Q=\frac{\omega L}{R} & \geq 7.85 \times 10^{3} \text { @ } 2 \mathrm{MHz} \\
& \geq 1.17 \times 10^{5} \text { \& } 30 \mathrm{MHz}
\end{aligned}
$$


For $\mathrm{L}_{2}=211 \mu \mathrm{H}$ we have: $\mathrm{C}_{2 \mathrm{MHz}}=3.00 \times 10^{-11}=30 \mathrm{pF}$

$$
\mathrm{C}_{30 \mathrm{MHz}}=1.33 \times 10^{-13}=0.13 \mathrm{pF}
$$

At $2 \mathrm{MHz}$ :

$$
\frac{1}{Q_{2}} C_{2}=3.82 \times 10^{-15} \mathrm{~F} \times \frac{\partial \delta}{\partial C}=3.21 \times 10^{-6} \mathrm{~m}=3.2 \mu \mathrm{m}
$$

At $30 \mathrm{MHz}$ :

$$
\frac{1}{Q_{30}} \quad C_{30}=1.14 \times 10^{-18} \mathrm{~F} \times \frac{\partial \delta}{\partial \mathrm{C}}=9.56 \times 10^{-10} \mathrm{~m} \cong 9.6 \AA
$$

The above calculation shows that for the vibration of dielectric to alter the capacitance by fess than $1 / Q$ requires vibration amplitudes of less than $3 \mu \mathrm{m}$ at $2 \mathrm{MHz}$ and $10 \mathrm{~A}$ at $30 \mathrm{MHz}$. Actually the resonant frequency $\left(\sim \mathrm{c}^{1 / 2}\right)$ is the important quantity allowing, respectively, $10 \mu \mathrm{m}$ and $100 \AA$ vibration amplitudes. This indicates that, especially for the higher frequencies, a filter geometry with a large immunity to vibration must be used.

Similarly, to estimate the change of the filter performance due to vertical vibration of the capacitor plates, we consider the effective capacitance in the tank circult shown in Fig. 8.

$$
c=\frac{c_{2}{ }^{i} c_{2}{ }^{o}}{c_{2}{ }^{i}+C_{2}{ }^{\circ}}=\frac{\varepsilon}{d},\left(\frac{A_{i} A_{0}}{A_{i}+A_{o}}\right)
$$

where $\varepsilon_{0}$ is the permittivity in vacuum, $d$ the separation spacing between two capacitor plates, and $A$ the area of the plate. The change of capacitance due to the vibration is

$$
\frac{\partial C}{\partial d}=\frac{-\varepsilon_{o}}{d^{2}}\left(\frac{A_{i} A_{o}}{A_{i}+A_{0}}\right)
$$

The notch frequency of the filter is given as

$$
f_{0}=\frac{1}{2 \pi \sqrt{L_{2} C}}
$$


which can be approximated to $1 / 2 \pi \sqrt{\mathrm{L}_{2} \mathrm{C}}$ for the $\mathrm{K}$ used in the present design. From these equations the effect of detuning can be calculated. The tolerable vibration is given as

$$
\mathrm{d}_{\mathrm{T}}=\frac{\mathrm{C}}{\mathrm{Q}} / \frac{\partial \mathrm{C}}{\partial \mathrm{d}}
$$

The major element parameters and tolerable vibration magnitudes are listed in Table IV for two filters at different $\mathrm{L}_{2}$ and four frequencies.

TABLE IV

\begin{tabular}{lccccccc}
\hline $\begin{array}{c}\mathrm{L}_{2} \\
(\mu \mathrm{H})\end{array}$ & $\begin{array}{c}\mathrm{f}_{\mathrm{O}} \\
(\mathrm{MHz})\end{array}$ & $\begin{array}{c}\mathrm{C} \\
(\mathrm{pF})\end{array}$ & $\mathrm{Q}$ & $\begin{array}{c}\mathrm{d}^{\mathrm{N}} \\
(\mathrm{m})\end{array}$ & $\begin{array}{c}\frac{\partial \mathrm{d}}{\partial \mathrm{d}} \\
(\mathrm{pF} / \mathrm{mm})\end{array}$ & $\begin{array}{c}\mathrm{d}_{\mathrm{T}} \\
(\mathrm{mm})\end{array}$ & $\begin{array}{c}\mathrm{R}_{2} \\
(\Omega)\end{array}$ \\
\hline 211 & 2 & 30 & $7.9 \times 10^{3}$ & $0.10 \times 10^{-3}$ & 300.0 & $0.013 \times 10^{-3}$ & 0.34 \\
\hline & 4.47 & 6 & $1.7 \times 10^{4}$ & $0.53 \times 10^{-3}$ & 11.3 & $0.031 \times 10^{-3}$ & 0.34 \\
\hline & 4 & 63.3 & $1.6 \times 10^{4}$ & $0.05 \times 10^{-3}$ & 1266.0 & $0.0002 \times 10^{-3}$ & 0.04 \\
\hline & 30 & 1.13 & $1.2 \times 10^{5}$ & $2.79 \times 10^{-3}$ & 0.4 & $0.024 \times 10^{-3}$ & 0.04 \\
\hline
\end{tabular}

${ }^{*}$ Calculated base on the effective area $A=\frac{A_{i} A_{0}}{A_{i}{ }^{+A_{0}}}=\frac{7.055 \times 7.183}{7.055+7.183} \times 10^{-4}$

$=3.56 \times 10^{-4} \mathrm{~m}^{2}$

The calculations showed that the mechanical stability of the mounting system is an important factor for long term stable tuning to be establisshed. This effect is especially pronounced when the capacitor is tuned to higher capacitances. 


\title{
B. SUPERCONDUCTING FILM PREPARATION AND
}

\author{
CHARACTERIZATION
}

\section{SUBSTRATE}

When choosing a substrate onto which films for the superconducting filter will be deposited, several factors must be taken into consideration. The films will be $\mathrm{Nb}$ and its compounds. A substrate should be chosen with a coefficient of thermal expansion $B$ similar to that of the film, which for $\mathrm{Nb}$ and its compounds ranges from $\sim 7$ to $9 \times 10^{-6}$ per ${ }^{\circ} \mathrm{C}$. This helps minimize thermal mismatch which can unduly stress the superconducting film causing deterioration of the superconducting properties and/or film lift off. Film lift off due to stress can be particularly troublesome during the pattern etching process. Filter performance is dependent on both the dielectric constant and the loss tangent and must be considered in choosing a substrate material.

Table $\mathrm{V}$ lists some of the substrate materials being considered along with the properties of interest. The maximum useable operating temperature is shown in this table since the A15 materials must be made at temperatures of about $800^{\circ} \mathrm{C}$. The substrate must be able to withstand these temperatures -without melting, outgassing, changing its electrical properties, etc. The dielectric constant and loss tangent are room temperature values. It is expected that the loss tangent should decrease with decreasing temperature although the only measured value at low temperatures is that of Lucalox at $\sim 15 \mathrm{~K}$ with a loss tangent of $1.4 \times 10^{-6}$ reported by Siegel, et. al (1). This is a two order of magnitude reduction over room temperature values. The dielectric constant should be maximized and the loss tangent minimized. . This helps improve the $Q$ of the circuit and the range over which it can be tuned.

\section{SUBSTRATE HEATING}

Since it is necessary to form $\mathrm{Nb}_{3} \mathrm{Sn}$ in $\mathrm{film}$ form at substrate temperatures ranging from 700 to $900^{\circ} \mathrm{C}$, a substrate heater capable of operating at these temperatures is required. For substrates of less than 1 "diameter, a simple strip heater consisting of, e.g., $0.002^{\prime \prime}$ thick by $1^{\prime \prime}$ wide $x 4^{\prime \prime}$ long tantalum foil capable of passing up to 100 Amps of ac current is perfectly adequate. However, when one or more discs of '2" diameter must be uniformly heated, the task becomes considerably more difficult due to radiation losses which go as $\mathrm{T}^{4}$ and to the ability of heating materials to withstand these temperatures.

Two designs have evolved which are presently in the process of evaluation. The first involves radiation heating of a $\mathrm{Cu}$ or $\mathrm{Ni}$ plate using a 1200 Watt Quartz lamp. Preliminary tests indicate top surface temperatures in excess of $800^{\circ} \mathrm{C}$ are possible, however surface temperatures of the substrates themselves have been measured to be about $200^{\circ} \mathrm{C}$ lower at $1 \mathrm{KW}$ input power. This heater works very well at about $500^{\circ} \mathrm{C}$ substrate surface 
TABLE $\nabla$

Substrate Materials

\begin{tabular}{lcclc} 
Material & $\begin{array}{l}\text { Max Usable } \\
\text { Temperature }\end{array}$ & $\begin{array}{c}\text { B } \\
\times 10^{-0}\end{array}$ & $\begin{array}{l}\text { Dlelectric } \\
\text { Lonstant }\end{array}$ & $\begin{array}{l}25^{\circ} \mathrm{C} \\
\text { Loss } \\
\text { l'angent }\end{array}$ \\
\hline & ${ }^{\circ} \mathrm{C}$ & $\begin{array}{c}20-800^{\circ} \mathrm{C} \\
\text { per }{ }^{\circ} \mathrm{C}\end{array}$ & $\begin{array}{l}\text { relative to } \\
\text { free space }\end{array}$ & $\times 10^{-4}$ \\
\hline
\end{tabular}

Fused Silica

(Suprasi1)

$\mathrm{Al}_{2} \mathrm{O}_{3}$

(Single Crystal)

Macor

G1ass Ceramic

Lucalox

(Polycrystalline

$\mathrm{Al}_{2} \mathrm{O}_{3}$ )

Rutile

(Polycrystalline

$\mathrm{TiO}_{2}$ )
800

0.55

2000

$7-9$

$10.5-11.5$

5.9

$4 n . n$

1000

2040

7.0

10.0

1.5

1000

9.0

85

5.0 
temperature and all the $\mathrm{Nb}$ on fused silica were made using this heater at $500^{\circ} \mathrm{C}$.

The second design involves the use of thermocoax heating elements which have been brazed into grooves cut into the back side of a $\mathrm{Ni}$ or $\mathrm{Cu}$ plate as shown in Fig. 17. The top of such a plate has been machined flat and polished in order to lower its emissivity. The plate also contains a number of tapped holes for attaching substrates clamps. The entire unit can be placed in a radiation shield to reduce losses from the sides and bottom. This unit has been tested to about $750^{\circ} \mathrm{C}$ substrate surface temperature. The heater has failed at the joint between the external lead in wires and the Nickel Chromium heater wire. Methods of improving this joint are currently being tested. This type of plate heating appears to be the most promising and further refinements of the basic design are under consideration.

\section{SUPERCONDUCTING FILMS AND THEIR PROPERTIES}

Final specifications call for a superconducting filter operating in a closed cycle refrigerator at temperatures greater than 10K. To meet this requirement $\mathrm{Nb}_{3} \mathrm{Sn}$ films with $\mathrm{T}_{\mathrm{c}} \sim 17.5 \mathrm{~K}$ will be used. These films will be fabricated by magnetron sputtering in a vacuum system still being constructed and described elsewhere in this report.

a. Niobium. In order to evaluate the feasibility of making the various filter elements and measuring their properties, Niobium was chosen as the test material. It is a type II material like $\mathrm{Nb}_{3} \mathrm{Sn}$, has a $\mathrm{T}_{\mathrm{C}}$ of $\sim 9.3 \mathrm{~K}$, is easily made with our existing magnetron sputtering system, has a thermal expansion coefficient similar to $\mathrm{Nb}_{3} \mathrm{Sn}$, can be etched with the same solution as $\mathrm{Nb}_{3} \mathrm{Sn}$, can be made with a critical current density $\geq 10^{6}$ Amps $/ \mathrm{cm}^{2}$ at $4.2 \mathrm{~K}$ and has a microstructure similar LO $\mathrm{Nb}_{3} \mathrm{Su}_{1}$. Takle VI gives the deposition parameters of the material prepared for this program.

TABLE VI

Niobium Film Preparation Conditions

Target Material:

Sputtering Pressure:

Sputtering Gas:

Targel-Subslrate Spacing:

Substrate Temperature:

Deposition Rate

Target Power Input:

Substrate Material:

Thickness:
$99.95 \%$ pure polycrystalline $\mathrm{Nb}$

\section{5 mtorr}

Argon

$3^{\prime \prime}$

$200-525^{\circ} \mathrm{C}$

$100 \AA / \mathrm{sec}$

$5.4 \mathrm{KW}$

Pyrex and Fused Quartz

$500 \mathrm{~nm}$ 


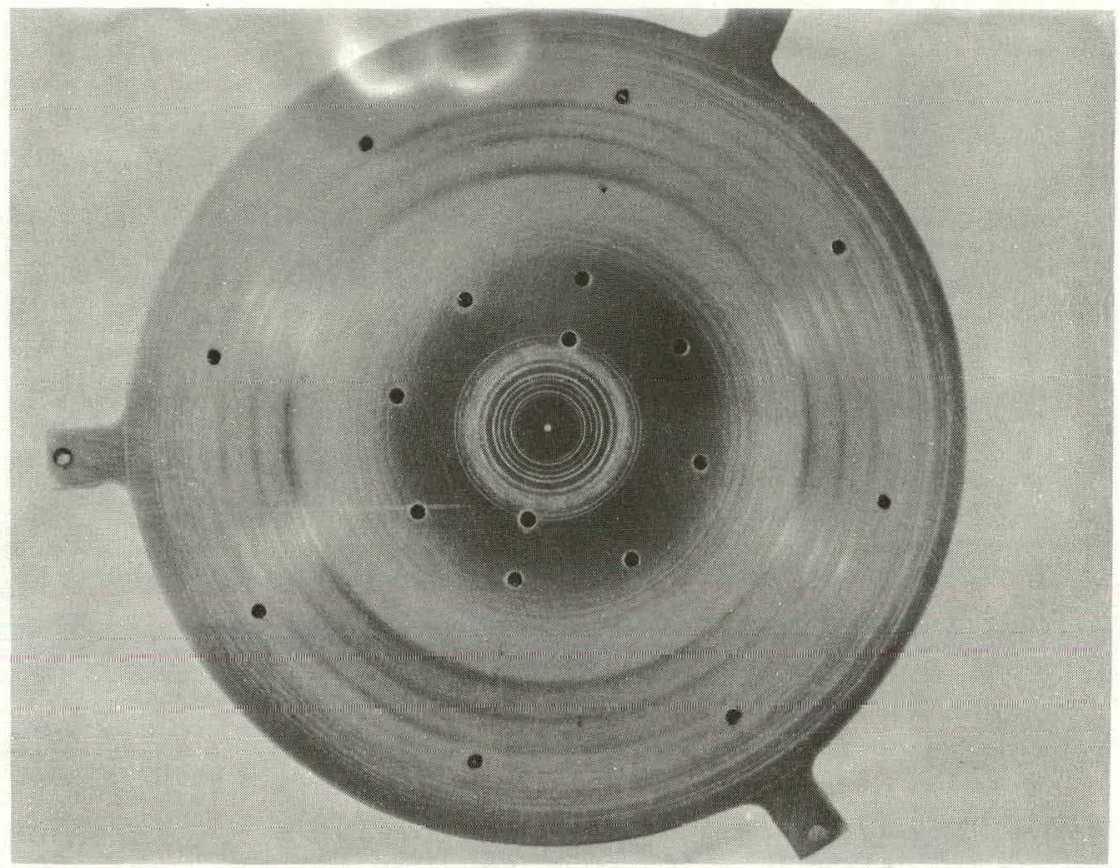

a.

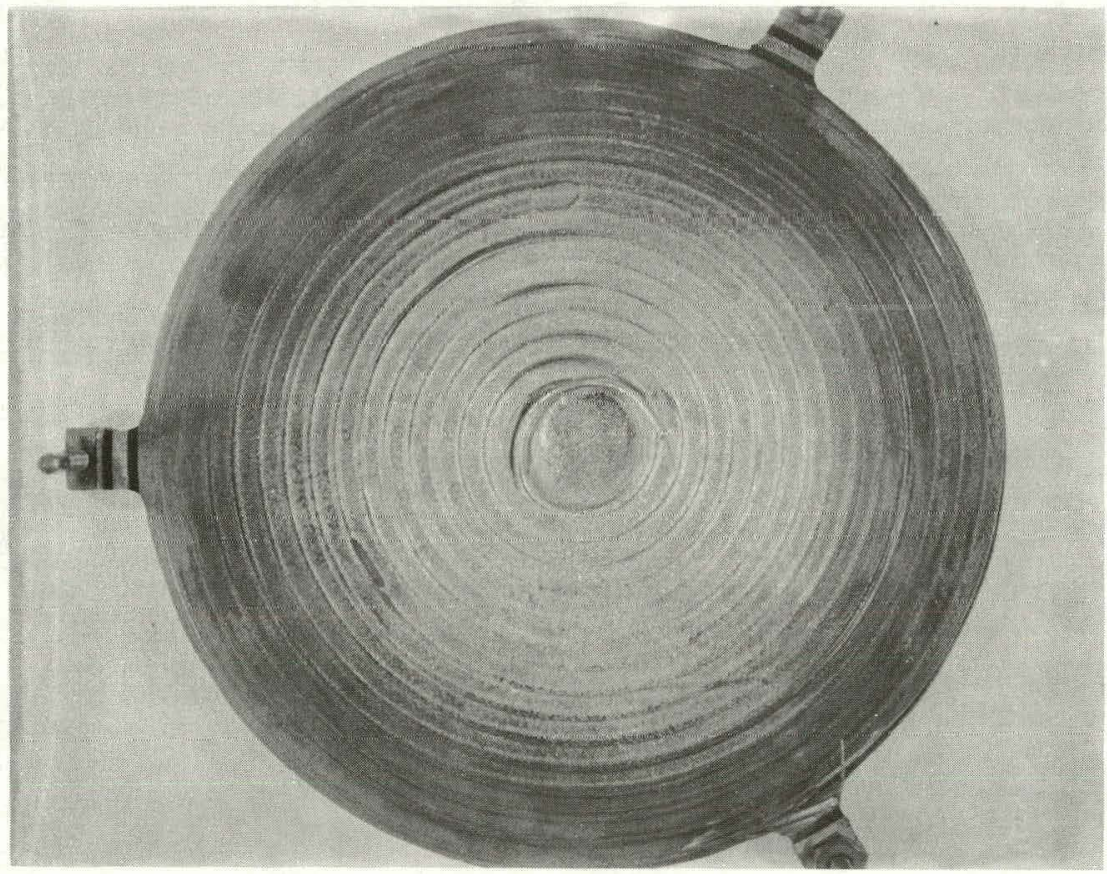

b.

Fig. 17 Substrate heater using thermocoax heating elements embedded in $\mathrm{Ni} / \mathrm{Cu}$ plate. 
The vacuum chamber is pumped to $<5 \times 10^{-7}$ Torr, followed by bringing the substrate up to the desired operating temperature. During this period the pressure can rise to as high as $1 \times 10^{-5}$ Torr after which it decreases. Table VII gives a breakdown of the residual gases in the system just prior to introduction of the sputtering gas, showing clearly that the dominant gas is water vapor.

TABLE VII

Partial Pressures of Residual Gases in Vacuum System

\begin{tabular}{cc}
\hline Tota1 Pressure $=2.1 \times 10^{-6}$ Torr; $\mathrm{T}_{\mathrm{S}}=495^{\circ} \mathrm{C}$ \\
\hline Residua1 Gas Species & $\begin{array}{l}\text { Partial Pressure } \\
\text { AMU }\end{array}$ \\
\hline 2 & $\begin{array}{c}\text { x } 10^{-7} \text { Torr } \\
12\end{array}$ \\
18 & 3.7 \\
28 & 15.0 \\
32 & 0.6 \\
44 & 0.02 \\
$50-100$ & 0.3 \\
\hline
\end{tabular}

The presence of oxygen in the sputtering chamber due to background, dissociation of water vapor and contribution from the sputtering gas can have a significant effect on the quality of $\mathrm{Nb}$ films. Koch, et. al. have shown the $\mathrm{T}_{\mathrm{c}}$ of $\mathrm{Nb}$ is depressed by one degree per atomic precent oxygen in the film. A more sensitive measure of film quality is the rcsidual resistivity just above $\mathrm{T}_{\mathrm{c}}$ which can be expressed in terms of the resistivity ratio $\gamma \equiv \rho_{300} / \rho_{\mathrm{T}_{C}}$. The larger this number, the lower the impurity content of the film and hence the better the film quality.

In Table VIII we have 1 isted some of the electrical and superconducting properties of $\mathrm{Nb}$ films we have prepared by magnetron sputtering.

TABLE VIII

Properties of Sputtered Nb Films

$$
\begin{array}{lc}
\rho_{300} & 10-13 \mu \Omega \mathrm{Cm} \\
\rho_{300} / \rho_{\mathrm{Tc}} & 6 \text { to }>21 \\
\mathrm{~T}_{\mathrm{r}} & 9.26 \text { to } 9.47 \mathrm{~K}
\end{array}
$$


To further elucidate the characteristics of these films we have looked at the microstructure by both scanning and transmission electron microscopy. The results are shown in Figures 18 and 19. As expected, $\mathrm{Nb}$ films tend to grow in a dense columnar structure with grain size going from $<200 \AA$ for films prepared at $\mathrm{T}_{\mathrm{S}}$ of $200^{\circ} \mathrm{C}$ to $3000 \AA$ for a $\mathrm{T}_{\mathrm{S}}$ of $800^{\circ} \mathrm{C}$.

b. Niobium Nitride. One of the many difficulties of preparing high $\mathrm{T}_{\mathrm{c}}$ films has to do with substrate heating, particularly for non-planar geometries. NbN films having a bcc structure have been prepared by a number of authors at ambient temperatures (the equilibrium temperature reached by the substrate in the absence of direct substrate heating) using reactive sputtering. The process involves introducing a small partial pressure of nitrogen into the chamber during sputtering allowing a reaction between the niobium and nitrogen to form $\mathrm{NbN}$ on the substrate. These films have some rather interesting properties. T ${ }_{c}$ 's can range up to $15 \mathrm{~K}, \mathrm{H}_{\mathrm{c}_{2}}(0)>30$

Tesla residual resistivities $>300 \mu \Omega \mathrm{cm}$ and critical current densities in excess of $10^{7} \mathrm{~A} / \mathrm{cm}^{2}$ at zero field and $4.2 \mathrm{~K}$. In addition, the bcc structure of these films which is more stable than the Al5 structure of, e.g. $\mathrm{Nb}_{3} \mathrm{Sn}_{\text {, }}$ may prove more effective against degradation of the superconducting properties in intense radiation fields.

We have recently prepared $\mathrm{NbN}$ by $\mathrm{d} . \mathrm{c}$. magnetron reactive sputtering at a $\mathrm{T}_{\mathrm{S}}$ of $200^{\circ} \mathrm{C}$ using an $\mathrm{N}_{2}$ partial pressure of $1 \times 10^{-3}$ Torr with an Ar pressure of $3.2 \times 10^{-3}$ Torr. Power input was $0.86 \mathrm{KW}$. Using a weight gain method of measurement, film thickness was determined to be $1.76 \mu \mathrm{m}$ and deposition rate $1.73 \mathrm{~nm} / \mathrm{sec}(2.0 \mathrm{~nm} / \mathrm{sec} / \mathrm{kW})$. The $T_{c}$ of one of the films was measured using a 4 terminal resistive method and found to be 14 .3K with a transition width of $0.9 \mathrm{~K}$. This temperature should be high enough to allow filters made with $\mathrm{NbN}$ to operate with a closed cycle refrigerator. Further evaluation of these films will be carried out.

C. $\mathrm{Nb}_{3} \mathrm{Sn}$. As discussed in the introduction of this section, $\mathrm{Nb}_{3} \mathrm{Sn}$ is the superconductor agreed to for construction and evaluation of the final filter. The main advantage of this material is the high $\mathrm{T}_{\mathrm{c}}$ obtainable, typically $17.5 \mathrm{~K}$ to $18 \mathrm{~K}$ in thin film form using preparation techniques such as magnetron sputtering. We have previously reported(3) making films with $\mathrm{T}_{\mathrm{c}}$ onsets of $18 \mathrm{~K}, \Delta \mathrm{T}_{\mathrm{c}}$ of $0.5 \mathrm{~K}, \mathrm{Hc}_{2}(0)$ of 23 tesla and self-field $\mathrm{J}_{\mathrm{C}}(4.2 \mathrm{~K})$ of $1.5 \times 10^{7} \mathrm{~A} / \mathrm{cm}^{2}$. These films show dense columnar growth structures with very smooth surfaces, an example of which is shown in the SEM micrograph of Fig. 20.

One of the most difficult aspects of making good $\mathrm{Nb}_{3} \mathrm{Sn}$ films has to do with target construction. The very high target power inputs used in magnetron sputtering cause target heating producing preferential melting of $\mathrm{Sn}$ when it is tiled to the surface of a $\mathrm{Nb}$ base or mixed in the appropriate ratio with $\mathrm{Nb}$ powder in a composite powder target. The problem is particularly troublesome when using the down-sputtering geometry of our existing sputtering system. When the Sn begins melting it drips from the target onto the substrates, whether the target is tiled or mixed $\mathrm{Nb}-\mathrm{Sn}$ 


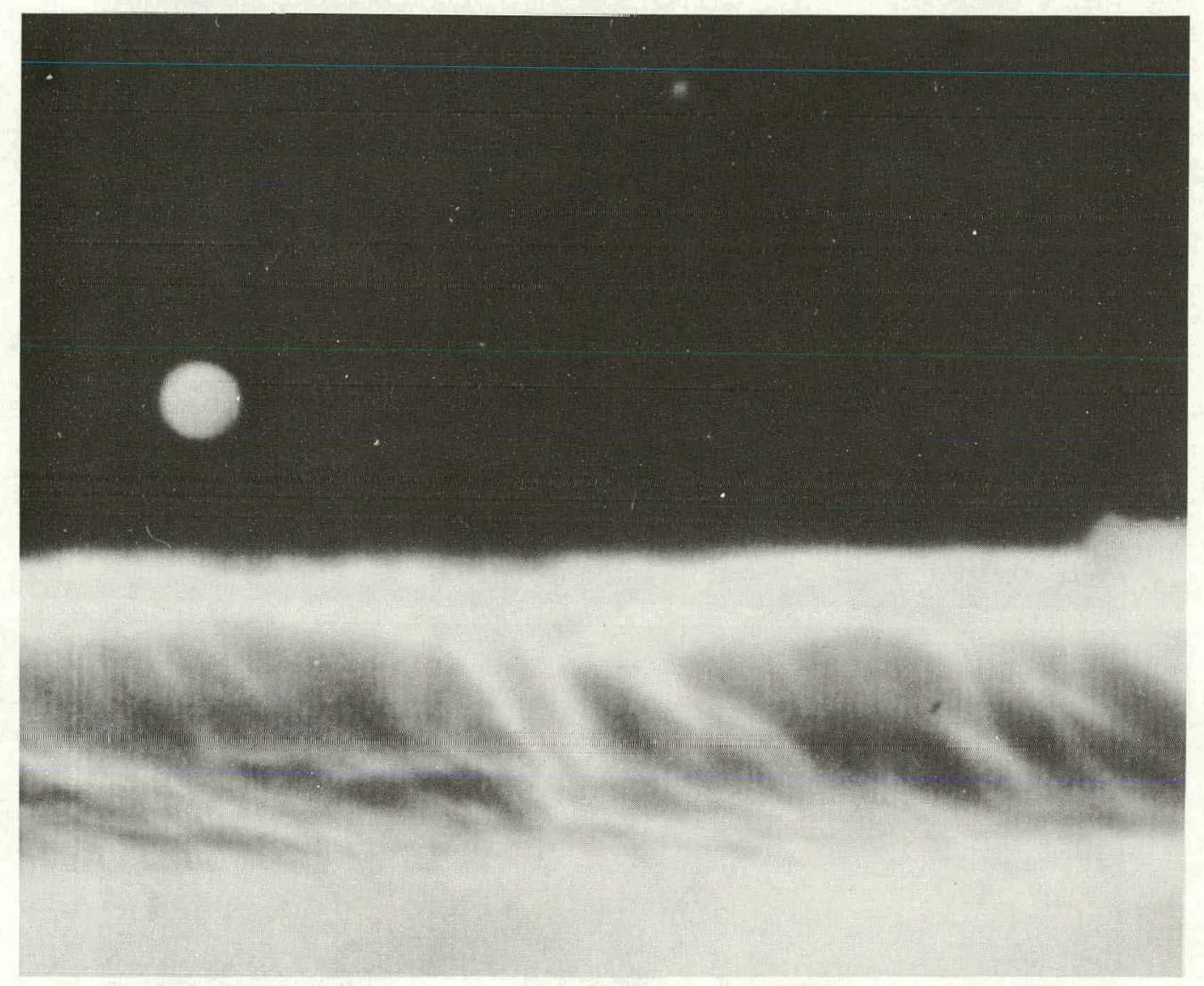

Fig. 18 Microstructure of sputtered Nb film 


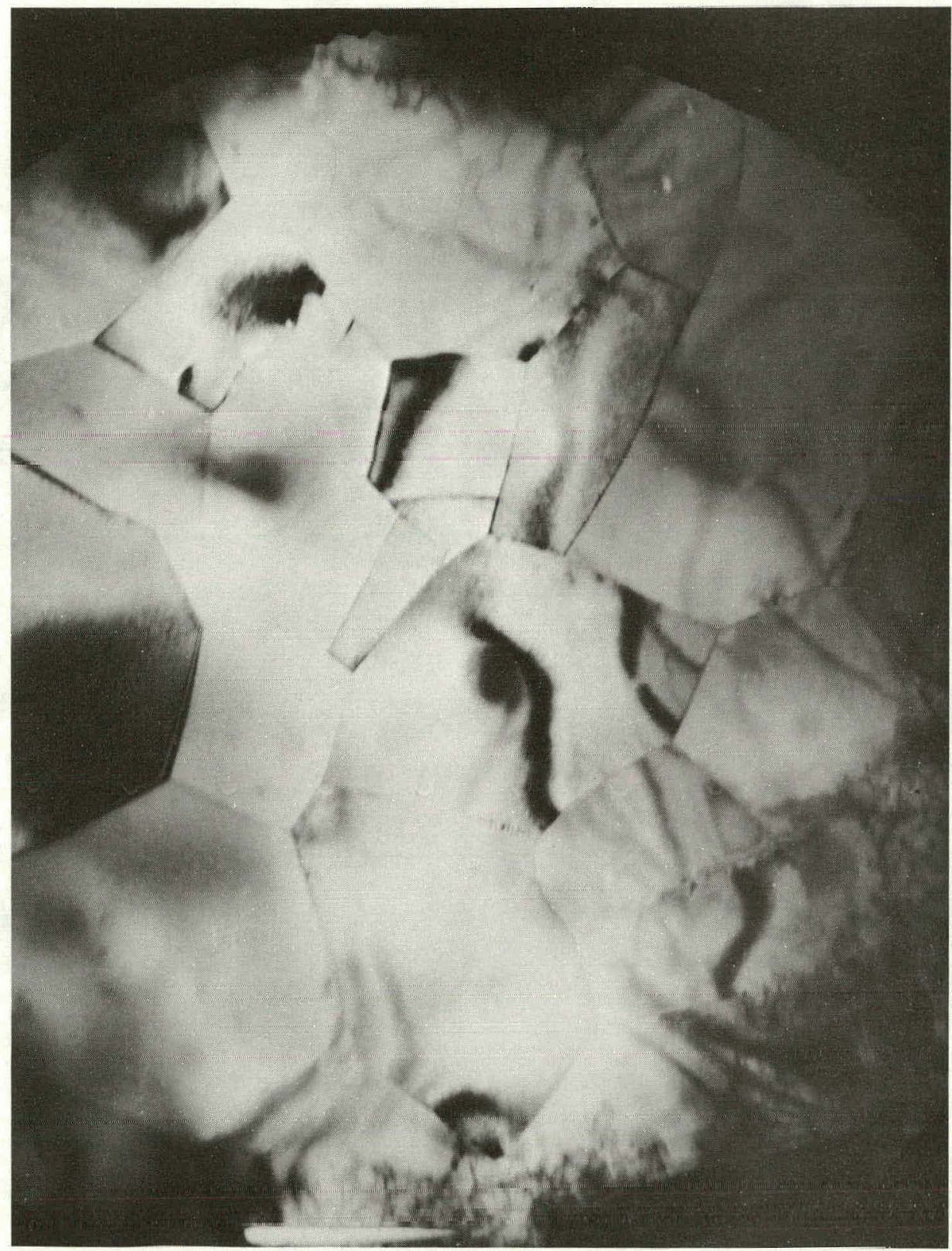

Fig. 19 Microstructure of sputtered $\mathrm{Nb}$ film. 
powder. Target composition changes with time resulting in decreasing film quality. To circumvent this problem we have devised a technique of powder target fabrication which ties the Sn powder up by reacting it with the $\mathrm{Nb}$ to form a higher melting point $\mathrm{Nb}-\mathrm{Sn}$ compound. An example of a reacted $\mathrm{Nb}_{3} \mathrm{Sn}$ powder target just prior to final machining is shown in Fig. 21 . This procedure has proven very successful in producing $\mathrm{Nb}_{3} \mathrm{Sn}$ films of very high quality. The main disadvantage is a tendency for the targets to crack during thermal cycling caused by the sputtering process. The target expands into the circumferential cooling ring during plasma heating causing target stress. Since $\mathrm{Nb}_{3} \mathrm{Sn}$ is very brittle, the target can only relieve the stress by cracking. The cracking generally has no effect on the sputtering process itself unless pieces of the target begin to fall off as is the tendency in the down-sputtering configuration. Sputtering upward, as will be the situation in the new system, becomes a necessity for $\mathrm{Nb}_{3} \mathrm{Sn}$. We anticipate beginning this short1y after completion of the new sputtering system in the fall of 1978 .

d. $\mathrm{Nb}_{3} \mathrm{Ge}$. To complete the discussion of materials suitable for filter construction, a few words about $\mathrm{Nb}_{3} \mathrm{Ge}$ are in order. This compound is more difficult to form since the stoichiometric $3: 1$, A-15 phase which gives the $23 \mathrm{~K} \mathrm{~T}$ is metastable at all substrate temperatures. However, under proper conditions the high $\mathrm{T}_{c}$ phase can be quenched in by a number of techniques including magnetron sputtering(4). Using $\mathrm{Nb}_{3} \mathrm{Ge}$, it should be possible to operate the filter at temperatures as high as $20 \mathrm{~K}$. We are presently refining our film fabrication techniques to permit film formation over a 4" diameter area such that the film properties at all points within the area are uniform and possess $\mathrm{T}_{\mathrm{c}}$ onsets $\geq 22 \mathrm{~K}$ with $\Delta \mathrm{T}_{\mathrm{c}}{ }^{\prime} \mathrm{s} \sim 0.5 \mathrm{~K}$. 


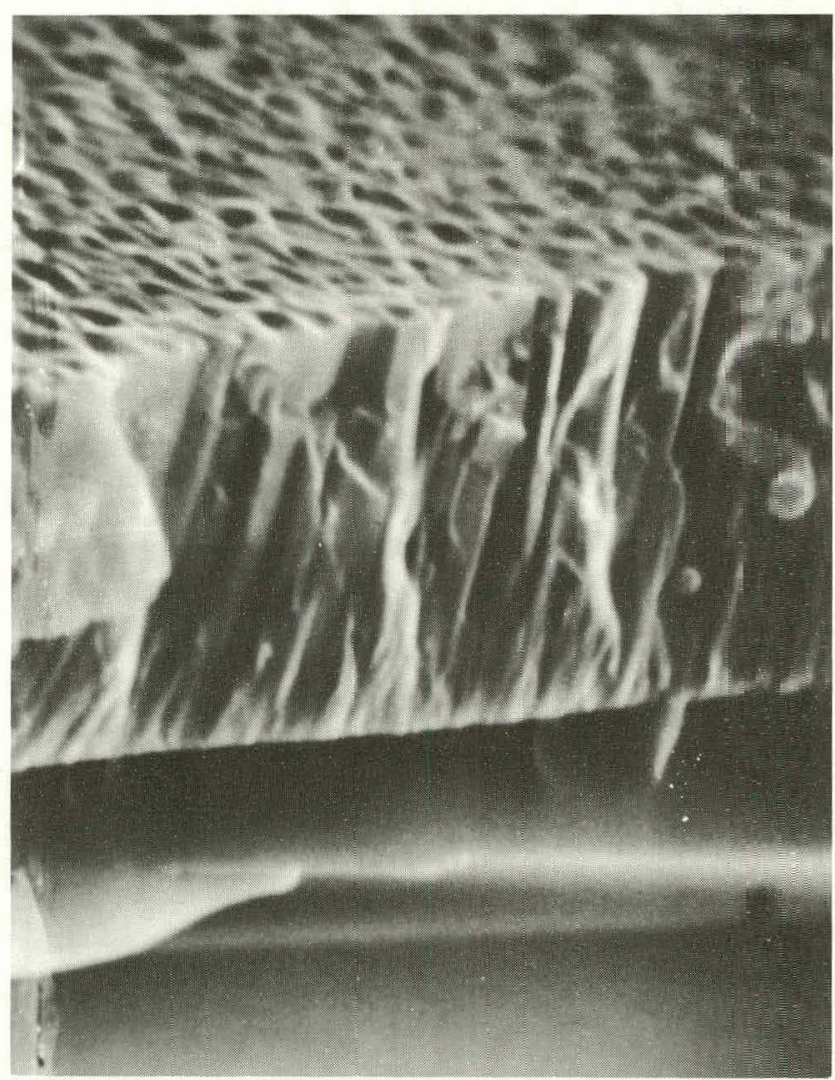

Fig. 20 SEM micrograph of $\mathrm{Nb}_{3} \mathrm{Sn}$ film inzicates columnar growth structure.

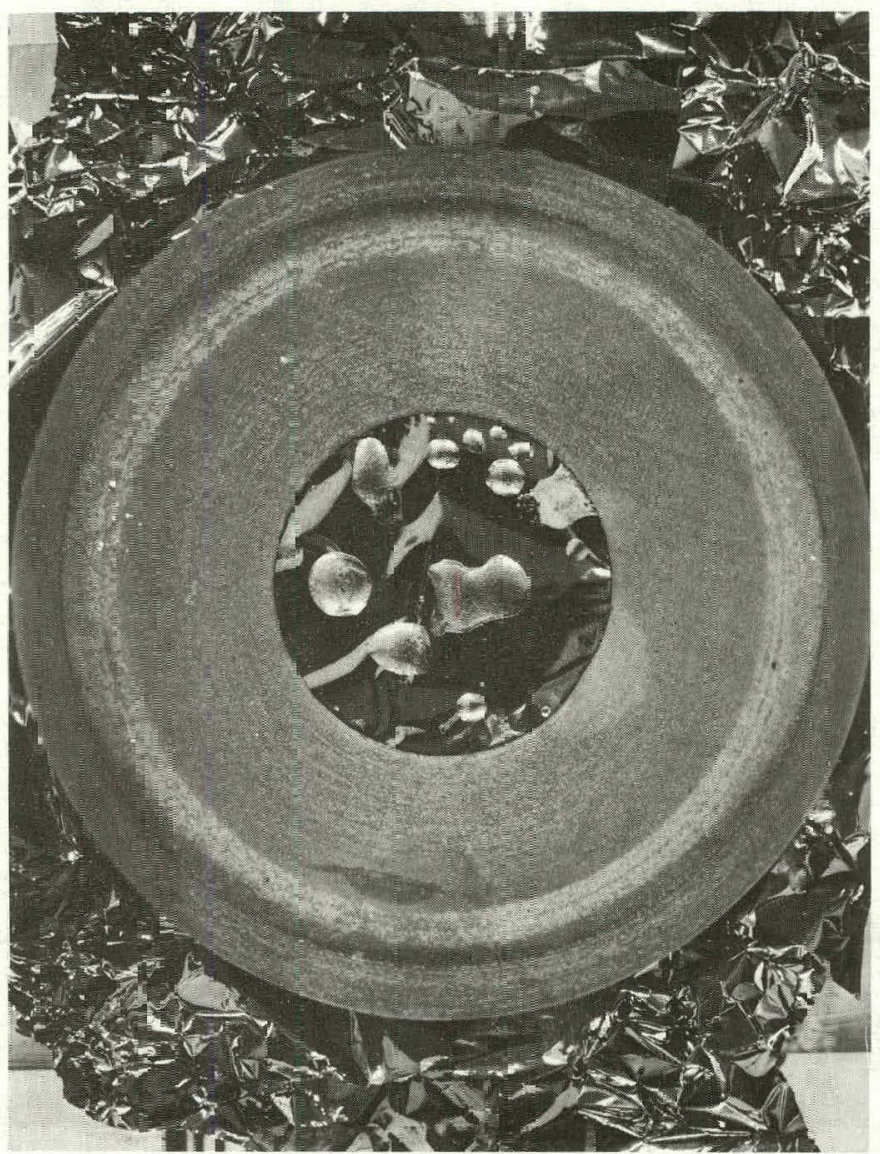

Fig. 2- Reacted $\mathrm{Nb}-\mathrm{Sn}$ powder sputtering target. 
IV. ETCHED PATTERN DEVELOPMENT

The planar geometry decided on for the prototype filter is most conveniently made by etching the appropriate patterns in films of superconducting material. To test this concept we coated several 2 inch diameter discs of Pyrex and Fused Silica with $0.5 \mu \mathrm{m}$ of $\mathrm{Nb}$. These discs were spin coated at $5000 \mathrm{rpm}$ for $25 \mathrm{sec}$ with undiluted Shipley 1350J positive working photoresist. Resist thickness was estimated to be about $1.5 \mu \mathrm{m}$. Following soft baking for $25 \mathrm{~min}$. at $90^{\circ} \mathrm{C}$, the films were exposed to light thru mask pattern $\mathrm{D} 1$. The exposure system consisted of a $500 \mathrm{~W}$ high pressure $\mathrm{Hg}$-arc $1 \mathrm{amp}$ with a lens system which afforded some degree of collimagtion. Initial efforts to expose the photoresist were made using the $4358 \mathrm{~A}$ line in the $\mathrm{Hg}$ spectrum. However, the intensity was such that sufficient exposure could not be obtained in a reasonable period of time. When the entire ultra violet spectrum of the lamp was used, acceptable exposures were obtained in about 10 minutes. The resist was then spray developed for $90 \mathrm{sec}$ with Shipley AZ-351 developer, rinsed with distilled water, dried and post-baked for 30 minutes at $130^{\circ} \mathrm{C}$ in a forced air oven.

Pattern etching was accomplished using a $\mathrm{Nb}$ etchant developed in our laboratory. It consists of 1 part $\mathrm{HNO}_{3}, 1$ part $\mathrm{H}_{2} \mathrm{SO}_{4}, 2$ parts $\mathrm{HF}$ and 4 parts $\mathrm{H}_{2} \mathrm{O}$. Etching is done at room temperature. It takes approximately $10 \mathrm{sec}$ to etch thru $0.5 \mu \mathrm{m}$ of $\mathrm{Nb}$. Patterns etched on Pyrex contained a number of defects. Typical examples are shown in Fig. 22. The black lines comprise the $\mathrm{Nb}$ film coil geometry and are typically about $35 \mu \mathrm{m}$ wide. The light area in between is the substrate. A rather poor polish and $\mathrm{HF}$ contained in the etchant produced the rough surface shown. It is assumed that the breaks in the film are due to lift off because of poor film to substrate adhesion. We have found this problem to be prevalent in $\mathrm{Nb}$ films deposited at $<300^{\circ} \mathrm{C}$ substrate temperature onto Pyrex.

When the substrate temperature is raised to about $500^{\circ} \mathrm{C}$ and the substrate material changed to fused silica substantial improvements in etched pattern quality result as shown in Fig. 23(a). In this case the photograph was taken using reflected light so that the bright area represents the coil. Fig. 23(b) is a high magnification (1250x) photo of a single line showing the regularity of the film edges. The entire coil is shown in Fig. 24 and consists of 71 turns, with center of turn to center of turn spacing of about $72 \mu \mathrm{m}$, turn crossection of $35 \mu \mathrm{m}$, turn crossection of $35 \mu \mathrm{m}$ by $0.5 \mu \mathrm{m}$, outer diameter of $3.18 \mathrm{~cm}$ and inner diameter of $2.1 \mathrm{~cm}$. The total length of conductor was estimated at $566 \mathrm{~cm}$. Some preliminary electrical measurements were made on this coil and are shown in Table IX.

We are presently preparing etched patterns for the entire filter and plan to make characteristic measurements of the assembly. 


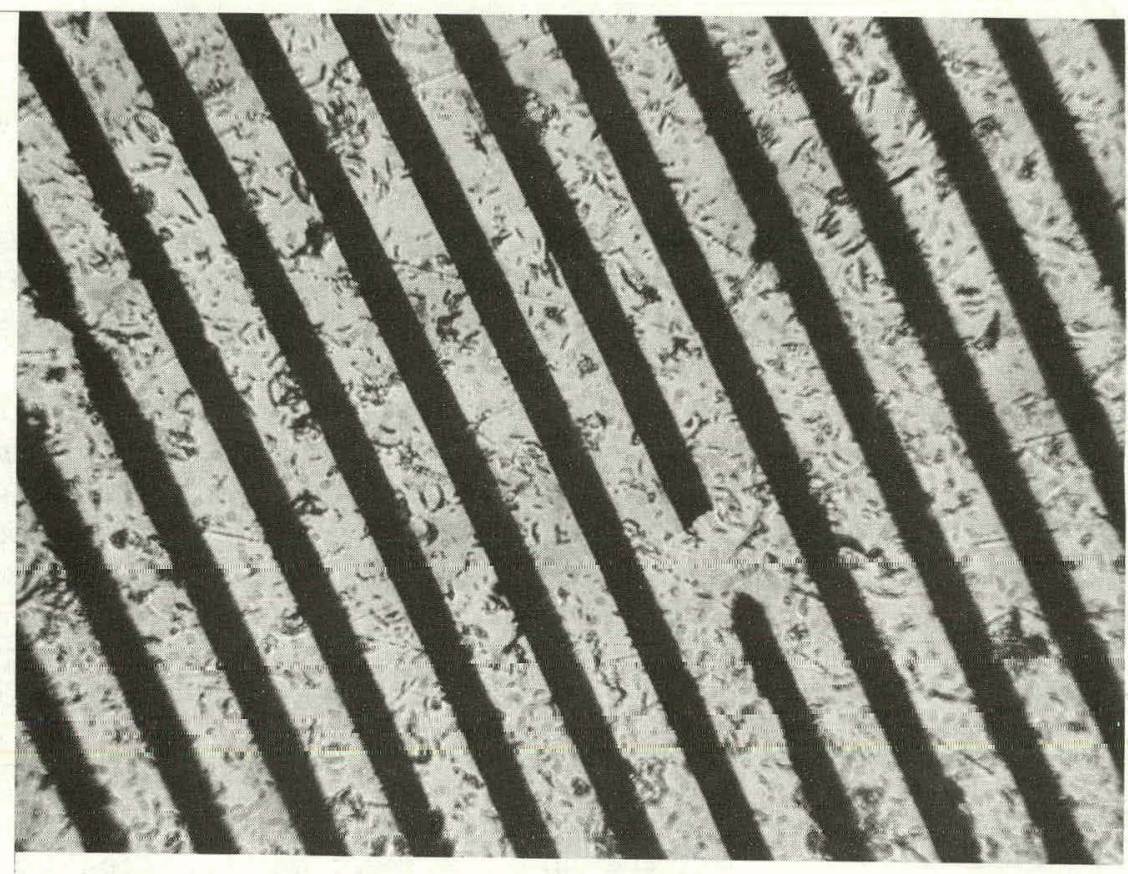

a.

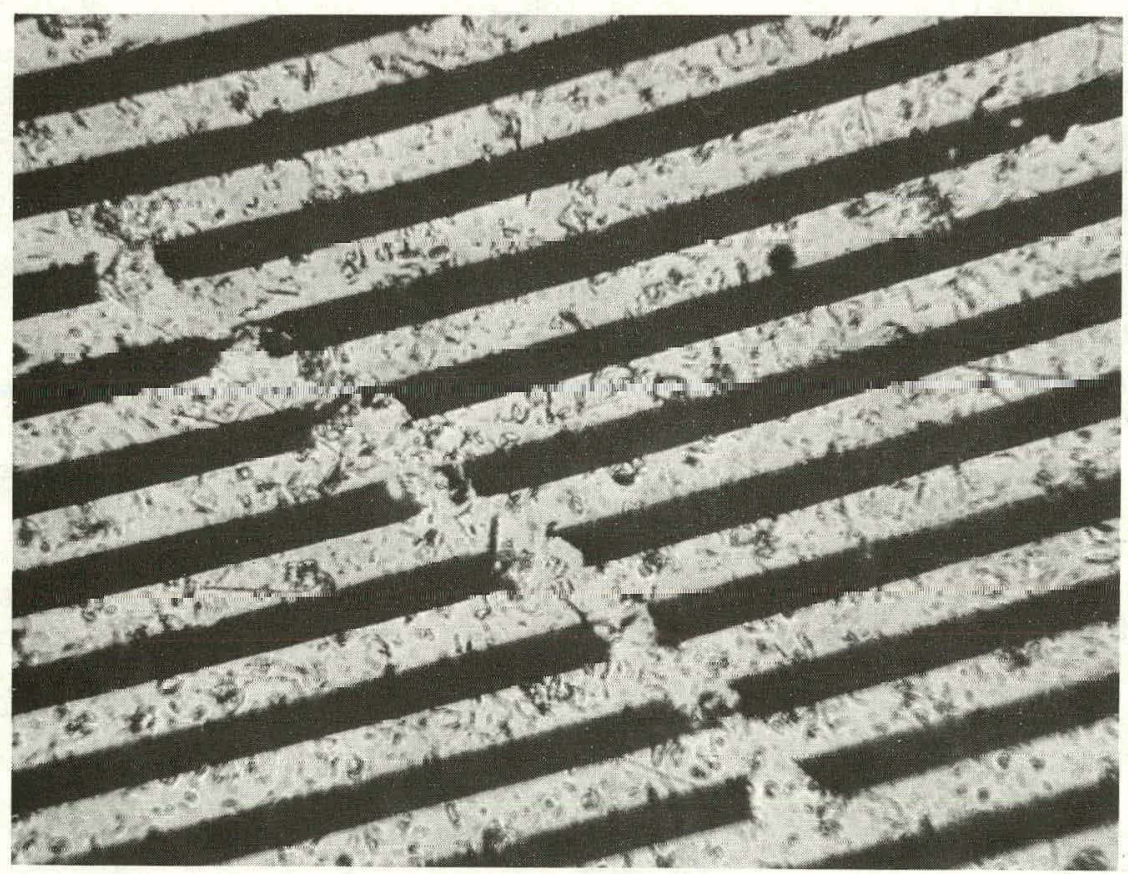

b.

Fig. 22 Examples of etching defects occurred in the $\mathrm{Nb}$ film coil on Pyrex substrate. 


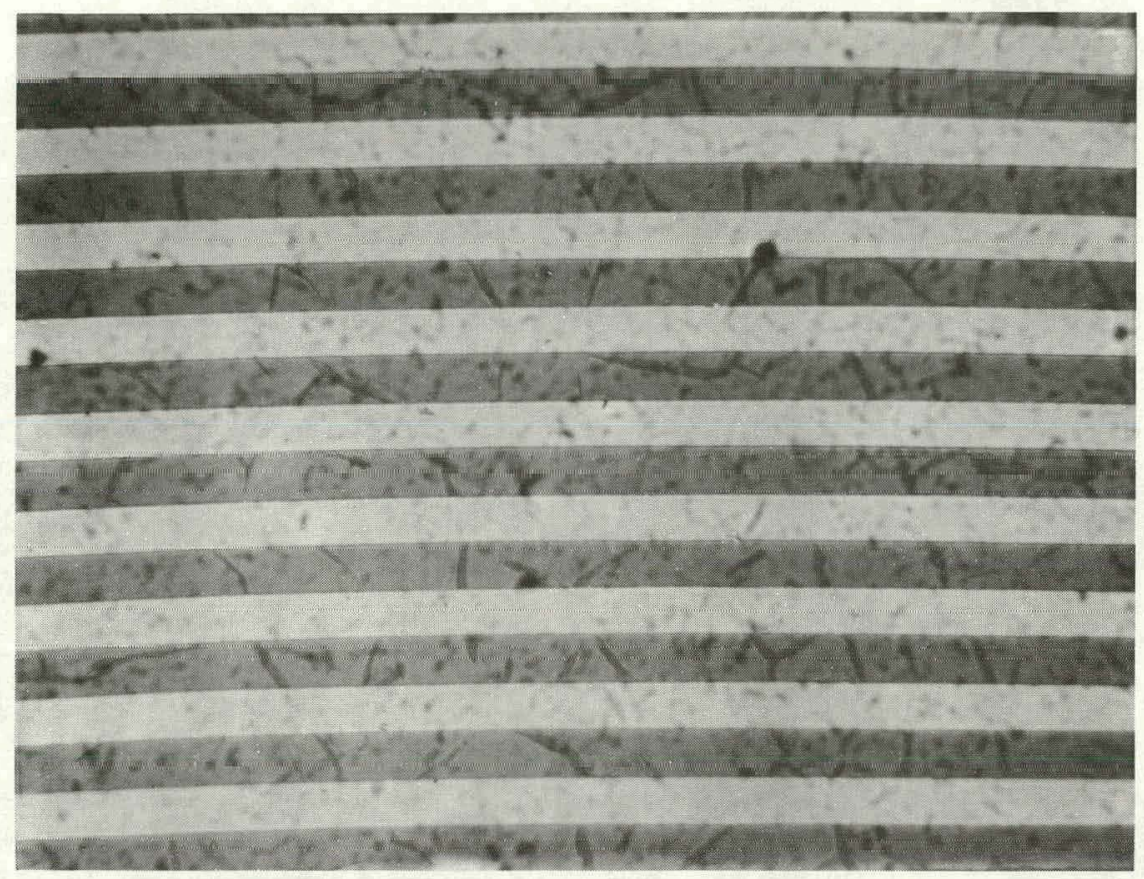

a.

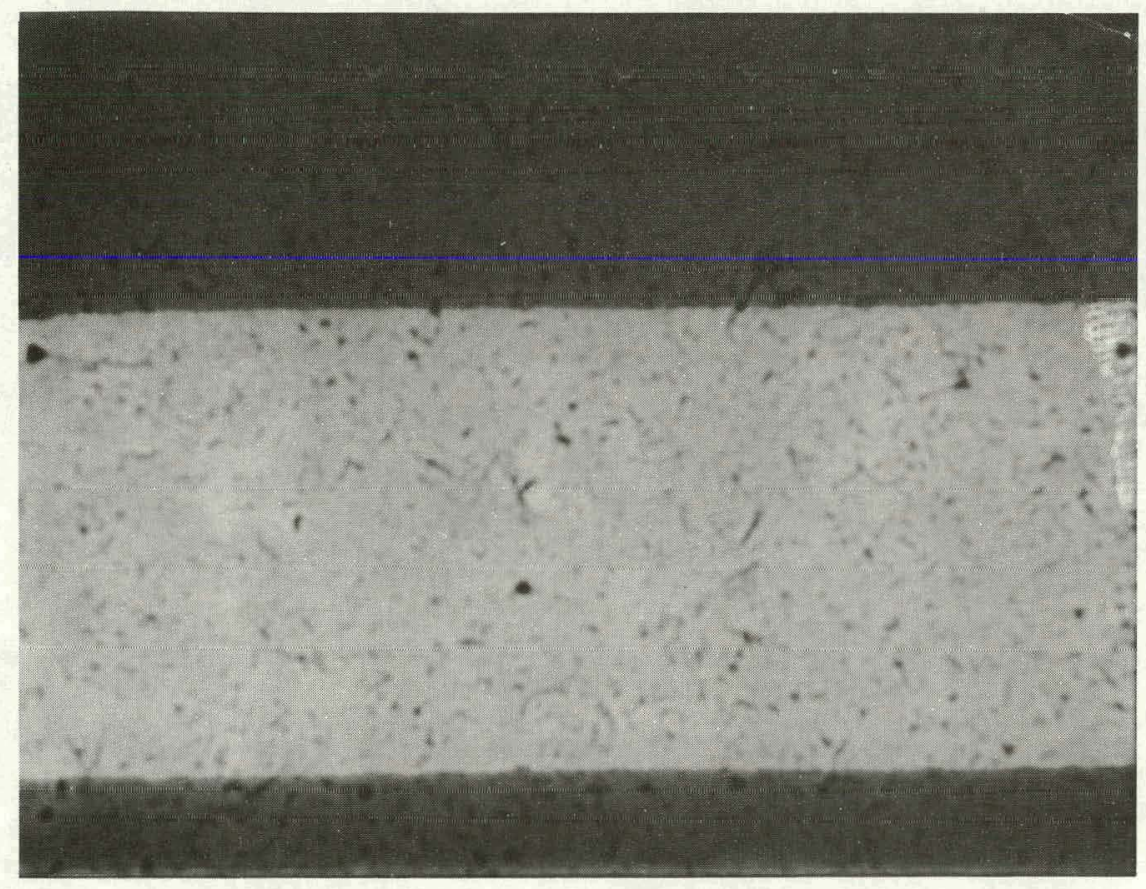

b.

Fig. 23 Improved etching pattern of $\mathrm{Nb}$ film coil on fused silica substrate. 


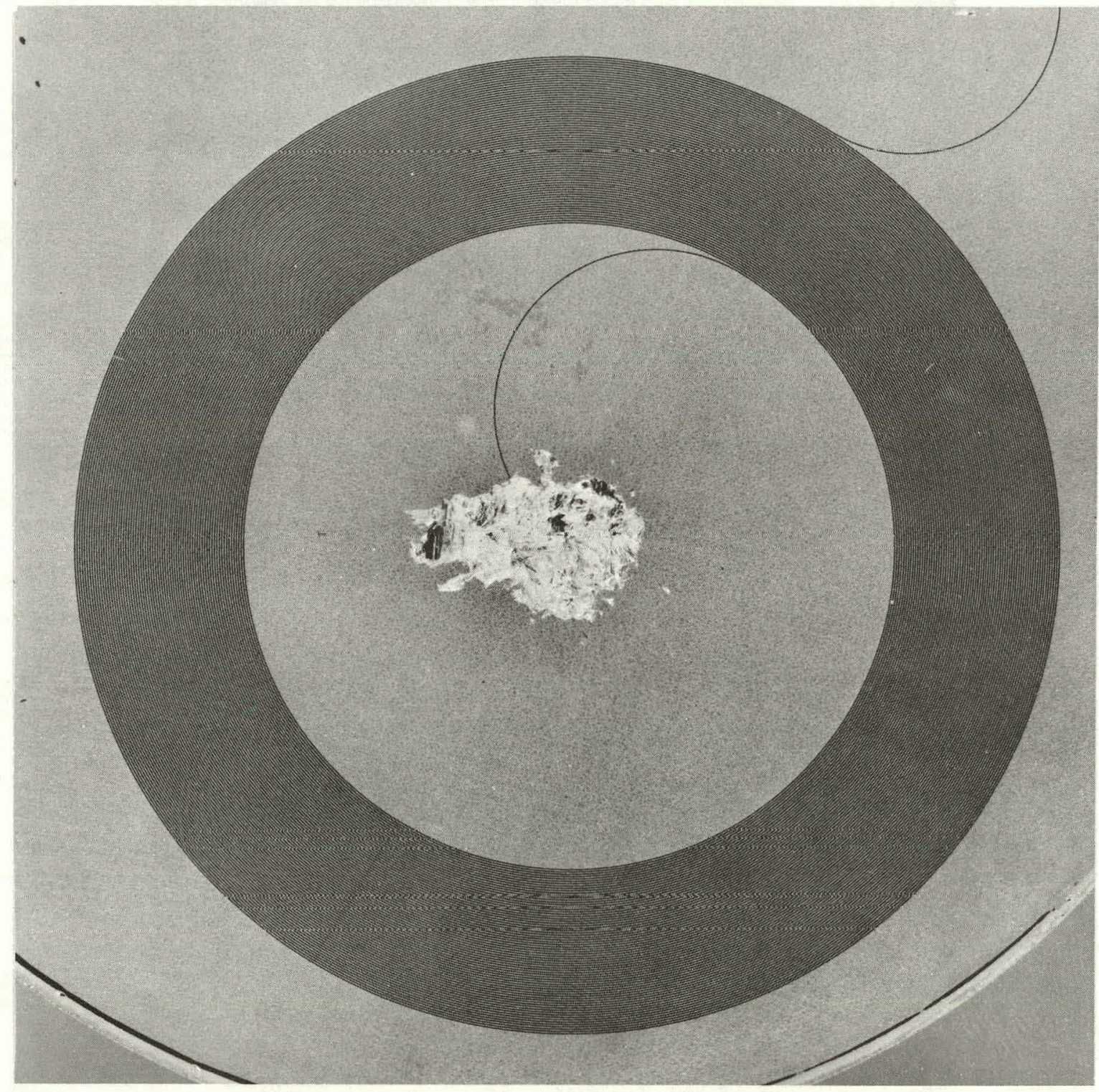

Fig. 24 Perfectly ectched Nb film coil. 


\section{TABLE IX}

\section{D1 Coil Performance Data}

\begin{tabular}{ccc}
\hline Room Temperature Resistance & $30.9 \mathrm{~K} \Omega$ \\
$77 \mathrm{~K}$ & $"$ & $8.0 \mathrm{~K} \Omega$ \\
$10 \mathrm{~K}$ & $"$ & $3.0 \mathrm{~K} \Omega$ \\
$\mathrm{R}_{300} / \mathrm{R}_{10}$ & 10.3 \\
Transition Temperalule & $9.3 \mathrm{~K}$ \\
Inductance at $4.2 \mathrm{~K}$ & $0.21 \mathrm{mH}$ \\
\hline
\end{tabular}




\section{FILM PREPARATION FACILITIES}

All superconducting films used in this program will be prepared by dc magnetron sputtering. The system employed in the early phases of the effort is an already existing facility consisting of a diffusion pumped liquid-nitrogen trapped, stainless steel vacuum chamber capable of attaining a base pressure in the $10^{-8}$ torr range. The chamber contains a single Varian 5 inch S-gun sputtering assembly mounted on the top plate of the chamber so as to sputter downward onto a substrate stage which can be either heated on cooled. Chromel-Alumel thermocouples monitor substrate temperatures while sputtering pressure is measured using a wide range ionization gauge or absolute capacitance manometer. $99.9999 \%$ pure Argon is used as the sputtering gas with sputtering pressures ranging from 3 to 100 mtorr. All sputtering is done under conditions of conclnuous Ar. flow using the diffusion pump at a throttled pumping speed of $70 \mathrm{l} / \mathrm{sec}$. Impurity gas content can be monitored during sputtering by means of a differentially pumped quadrupole mass spectrumeter. This system has been successfully used to make very high quality superconducting films of $\mathrm{Nb}, \mathrm{Nb}_{3} \mathrm{Sn}, \mathrm{Nb}_{3} \mathrm{Ge}$ and $\mathrm{NbN}$.

We are presently completing the design and construction of a new sputtering system consisting of a 24 inch diameter stainless steel chamber equipped with two S-guns mounted to allow upward sputtering and sequential film deposition without breaking vacuum. The chamber is being made at ANL and will be shipped to Varian for mating to a Model 3118 pumping module with two S-guns mounted on a 24 " diameter base plate. The system is expected back at ANL in early October, 1978 and should be functional for $f i l m$ deposition by November 1, 1978. All the $\mathrm{Nb}_{3} \mathrm{Sn}$ filter elements will be made in this system. 
REFERENCES

1. K. Siege1, R. Domchick and F. R. Arams, Proc. Symposium on the Physics of Superconducting Devices, 1967, Charlottesville, VA.

2. C. C. Koch, J. 0. Scarbrough, and D. M. Kroeger, Phys. Rev. B, 9, $888(1974)$.

3. R. T. Kampwirth, J. W. Hafstrom, and C. T. Wu, IEEE Trans. Magnetiçs Mag. 13 (1), 315 (1977).

4. R. T. Kampwirth, C. T. Wu and J. W. Hafstrom, Adv. Cryogenic Eng. 24, $465 .(1978)$. 
Internal:

M. V. Nevitt

B. Ancker-Johnson

D. C. Price

B. R. T. Frost

G. T. Garvey

D. Y. Smith
C. M. Falco (40)

A. B. Krisciunas ANL Contract File ANL Libraries (5) TIS Files (6)

Externa1:

DOE-TIC, for distribution per UC-38 (194)

Manager, Chicago Operations Office

Chief, Office of Patent Counsel

President, Argonne Universities Association

Solid State Science Division Review Committee:

R. J. Birgeneau, Massachusetts Inst. Technology

R. W. Balluffi, Massachusetts Inst. Technology

L. M. Falicov, U. California, Berkeley

C. P. Flynn, U. Illinois Urbana

D. M. Ginsberg, U. Illinois, Urbana

K. L. Kliewer, Iowa State U.

G. A. Russell, U. Missouri

J. Weertman, Northwestern U. 